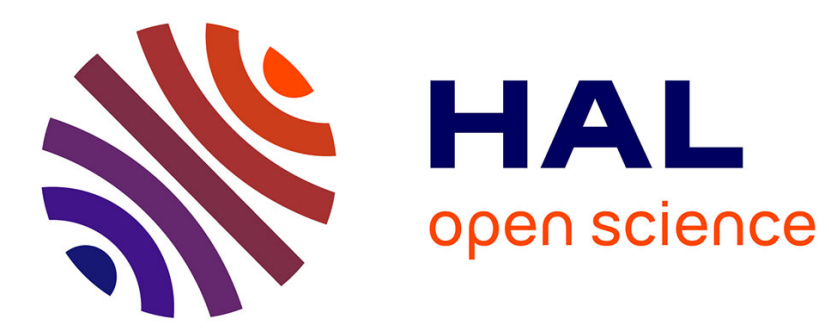

\title{
High thermoelectric figure of merit in well optimized YbyCo4Sb12
}

E Alleno, M Benyahia, J B Vaney, K Provost, V Paul-Boncour, J Monnier, Anne Dauscher, Bertrand Lenoir

\section{- To cite this version:}

E Alleno, M Benyahia, J B Vaney, K Provost, V Paul-Boncour, et al.. High thermoelectric figure of merit in well optimized YbyCo4Sb12. Journal of Materials Chemistry C, 2020, 47, 10.1039/D0TC03455J . hal-03024384

\section{HAL Id: hal-03024384 \\ https://hal.science/hal-03024384}

Submitted on 25 Nov 2020

HAL is a multi-disciplinary open access archive for the deposit and dissemination of scientific research documents, whether they are published or not. The documents may come from teaching and research institutions in France or abroad, or from public or private research centers.
L'archive ouverte pluridisciplinaire HAL, est destinée au dépôt et à la diffusion de documents scientifiques de niveau recherche, publiés ou non, émanant des établissements d'enseignement et de recherche français ou étrangers, des laboratoires publics ou privés. 


\title{
High thermoelectric figure of merit in well optimized $\mathrm{Yb}_{y} \mathrm{Co}_{4} \mathrm{Sb}_{12}$
}

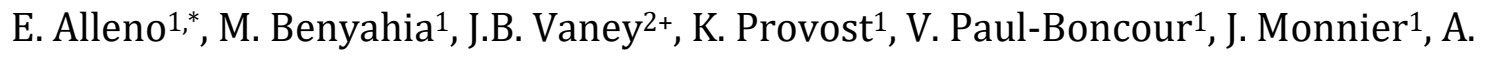 \\ Dauscher $^{2}$, B. Lenoir ${ }^{2}$ \\ 1 Univ Paris Est Creteil, CNRS, ICMPE, UMR 7182, 2-8, rue H. Dunant, F-94320 THIAIS, \\ France \\ 2 Université de Lorraine, Institut Jean Lamour, UMR 7198 CNRS-UL, 2 allée André \\ Guinier, 54011 NANCY, France
}

By implementing X-ray absorption spectroscopy among other techniques, ytterbium was inferred to display a valence of 2 in the thermoelectric $\mathrm{Yb}_{y} \mathrm{Co}_{4} \mathrm{Sb}_{12}$ skutterudites $(0.10$ $\leq y \leq 0.20)$. Consequently, the correlation $P F\left(A^{3+}\right)<P F\left(A^{2+}\right)<P F\left(A^{1+}\right)$ between the valence of the filler atom and the power factor $(P F)$ could be established in a generic set of $A_{y} \mathrm{Co}_{4} \mathrm{Sb}_{12}$ skutterudites ( $A=$ filler atom and electron donor). By grinding the $\mathrm{Yb}_{y} \mathrm{Co}_{4} \mathrm{Sb}_{12}$ samples under inert atmosphere prior to densification by Spark Plasma Sintering, no spurious oxidation of $\mathrm{Yb}$ occurred, conversely to what happens when grinding in air. This led to the effective ytterbium concentration being strictly equal to the nominal one, up to the solubility limit determined to be $y_{\text {lim }}=0.41 \pm 0.02 \mathrm{~mol} /$ formula unit when the $\mathrm{Yb}_{y} \mathrm{Co}_{4} \mathrm{Sb}_{12}$ compounds are synthesized at $1073 \mathrm{~K}$. The maximum $P F=4.2 \mathrm{~mW} \mathrm{~m}^{-1} \mathrm{~K}^{-2}$ at $300 \mathrm{~K}$ is reached in $\mathrm{Yb}_{0.15} \mathrm{Co}_{4} \mathrm{Sb}_{12}$, for the first time at the theoretically predicted electron concentration $n_{\text {opt }}=1.8 \pm 0.2 \times 10^{20} \mathrm{~cm}^{-3}$, thus evidencing the optimization of this compound. Finally, $\mathrm{Yb}_{0.15} \mathrm{Co}_{4} \mathrm{Sb}_{12}$ also displays the best thermoelectric properties in the series, with a figure of merit $Z T_{\max }=1.4$ and $P F=5.5 \mathrm{~mW} \mathrm{~m}^{-1} \mathrm{~K}^{-2}$ at $750 \mathrm{~K}$.

\footnotetext{
* Corresponding author: eric.alleno@icmpe.cnrs.fr

+ Current address: ICMCB, UMR 5026, 87 Avenue du Dr Schweitzer, 33608 PESSAC cedex, France
} 


\section{Introduction}

An all solid-state conversion of heat into electricity can be achieved by thermoelectric devices. The electrons or holes play the role of the charge and heat carrying fluid which circulates in the $n$ - and $p$-type semiconductors constituting these devices. Their compactness and high reliability compensate their current low practical efficiency $(<10 \%)$. They are considered for applications such as powering autonomous sensors or recycling the waste heat lost in industrial processes. Their efficiency depends on the dimensionless thermoelectric figure of merit $Z T$ of the $n$ - and $p$-type semiconductors. $Z T$ is defined by the relation $Z T=\alpha^{2} T / \rho \lambda$ with $\alpha$ the Seebeck coefficient or thermopower, $\rho$ the electrical resistivity, $\lambda$ the thermal conductivity and $T$ the absolute temperature. Materials displaying ZT values larger than 1 are considered as valuable for applications.

Good thermoelectric properties were initially discovered in $\mathrm{Ce}_{y} \mathrm{Co}_{4} \mathrm{Sb}_{12}$ and $\mathrm{Yb}_{y} \mathrm{Co}_{4} \mathrm{Sb}_{12}$ skutterudites by Morelli et al. ${ }^{1}$ and by Nolas et al. ${ }^{2}$, respectively. $n$-type $A_{\mathrm{y}} \mathrm{Co}_{4} \mathrm{Sb}_{12}(A=$ electropositive element $)$ indeed display maximum $Z T$ values larger than 1 at $650-750 \mathrm{~K}$ : for instance $Z T=1.0-1.3$ in $\mathrm{Ce}_{0.15-0.2} \mathrm{Co}_{4} \mathrm{Sb}_{12}{ }^{3,4}, Z T=1.1$ in $\mathrm{Ba}_{0.3} \mathrm{Co}_{4} \mathrm{Sb}_{12}{ }^{5}$ and in $\mathrm{In}_{0.25} \mathrm{Co}_{4} \mathrm{Sb}_{12}{ }^{6-10}$. The electropositive $A$-element fills the icosahedra formed by the antimony atoms in the crystallographic structure ( $\mathrm{LaFe}_{4} \mathrm{P}_{12}$ structure type, $I-3 m$ space group) and gives rise to low energy optical phonons ${ }^{11}$ that scatter heat carrying phonons, leading to rather low lattice thermal conductivity $\left(\lambda_{L} \sim 3 \mathrm{~W} \mathrm{~m}^{-1} \mathrm{~K}^{-1}\right.$ at $\left.300 \mathrm{~K}\right)$. The $A$ element also donates its electrons to the conduction bands of $\mathrm{CoSb}_{3}$, allowing the optimization of the power factor to large values $\left(P F=\alpha^{2} / \rho \sim 4 \mathrm{~mW} \mathrm{~m}^{-1} \mathrm{~K}^{-2}\right.$ at $\left.300 \mathrm{~K}\right)$. Improved maximum $Z T$ values ranging from 1.4 to 1.8 were recently reported in the $A_{\mathrm{y}} \mathrm{Co}_{4} \mathrm{Sb}_{12}(\mathrm{~A}=\mathrm{Sr}, \mathrm{In}, \mathrm{Ba}, \mathrm{La}, \mathrm{Ce}, \mathrm{Yb})$ skutterudites by introduction of extra phonon scattering processes arising from multifilling the antimony icosahedra by several 
different electropositive elements 12 or from nanostructuration (grain boundaries, nanoprecipitates...) ${ }^{10,13-19}$ or by a combination of both ${ }^{20-23}$.

Among the single-filled and non-nanostructured $n$-type $A_{\mathrm{y}} \mathrm{Co}_{4} \mathrm{Sb}_{12}$ skutterudites,

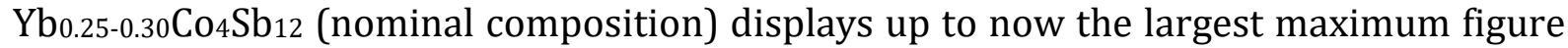
of merit $Z T=1.3-1.5$ at $750-800 \mathrm{~K}^{24-26}$. The reasons for these superior performances are yet only partially understood. The heavier atomic mass and the larger filling concentration limit (FCL) of the $\mathrm{Yb}$ atoms indeed lead to lower values of the lattice thermal conductivity $\left(\lambda_{L}=1.7-1.8 \mathrm{~W} \mathrm{~m}^{-1} \mathrm{~K}^{-1}\right.$ at $300 \mathrm{~K}$ in $\mathrm{Yb}_{\left.0.2-0.3 \mathrm{Co}_{4} \mathrm{Sb}_{12}\right)}{ }^{24-27}$ than in $\mathrm{Ba}_{0.25} \mathrm{Co}_{4} \mathrm{Sb}_{12}\left(\lambda_{L}=3.0 \mathrm{~W} \mathrm{~m}^{-1} \mathrm{~K}^{-1} \text { at } 300 \mathrm{~K}\right)^{28}$ and in $\mathrm{Ce}_{0.15} \operatorname{Co}_{4} \mathrm{Sb}_{12}\left(\lambda_{L}=2.3 \mathrm{~W} \mathrm{~m}^{-1} \mathrm{~K}^{-1}\right.$ at 300 $\mathrm{K})^{3,4}$, respectively. The FCL of $\mathrm{Yb}$ in $\mathrm{Yb}_{y} \mathrm{Co}_{4} \mathrm{Sb}_{12}$ had been theoretically predicted to be $y$ lim $=0.3^{29,30}$ but was latter experimentally revised to the nonconsensual values $y_{\lim }=0.26^{24}$, $y_{\text {lim }}=0.29^{26,31}$ or $y \lim =0.48^{25,27}$, depending on the synthesis temperature ${ }^{25}$ or method 27, 31. The large Seebeck coefficient occurring in $A_{y} \mathrm{Co}_{4} \mathrm{Sb}_{12}$ has been related to a large density of states effective mass, which remains independent on the nature of the filler atom ${ }^{32}$ and increases with the electron concentration ${ }^{32-34}$ from $\sim 1.5$ to $3.5 \mathrm{~m}_{\mathrm{e}}\left(\mathrm{m}_{\mathrm{e}}\right.$ is the bare electron mass). This large effective mass is qualitatively explained by a strong degeneracy of the conduction bands ${ }^{33-36}$. Based on this effective mass estimation and on either a single parabolic band model 10 or a more sophisticated 3 -band model ${ }^{34}$, an optimum electron density $n_{\text {opt }}=2 \times 10^{20} \mathrm{~cm}^{-3}$ has been found and expected to maximize the power factor in $A_{y} \mathrm{Co}_{4} \mathrm{Sb}_{12}(A=\mathrm{In}, \mathrm{Yb})$ at $300 \mathrm{~K}$. However, in $\mathrm{Yb}_{y} \mathrm{Co}_{4} \mathrm{Sb}_{12}$, the maximum power factor is not experimentally observed for $n_{\text {opt }}=2 \times 10^{20} \mathrm{~cm}^{-3}$ but for $n \sim 3-4 \times 10^{20}$ $\mathrm{cm}^{-3}$ and $y=0.20-0.3015,24,25,27,34$. The power factor also varies like the electronic mobility $(\mu)$ and it has been noticed that both quantities depend on the nature of the filler atom in $A_{y} \mathrm{Co}_{4} \mathrm{Sb}_{12}{ }^{32}$ : at $300 \mathrm{~K}$, optimized $\mathrm{Na}_{0.36} \mathrm{Co}_{4} \mathrm{Sb}_{12}$ displays a larger power factor and mobility $\left(P F \sim 4 \mathrm{~mW} \mathrm{~m}^{-1} \mathrm{~K}^{-2}\right.$ and $\mu \sim 40 \mathrm{~cm}^{2} \mathrm{~V}^{-1} \mathrm{~s}^{-1}$ at $300 \mathrm{~K}$ ) than optimized Ba0.16 $\mathrm{Co}_{4} \mathrm{Sb}_{12}$ 
$\left(P F \sim 3.5 \mathrm{~mW} \mathrm{~m}^{-1} \mathrm{~K}^{-2}\right.$ and $\mu \sim 30 \mathrm{~cm}^{2} \mathrm{~V}^{-1} \mathrm{~s}^{-1}$ at $\left.300 \mathrm{~K}\right)$. However, no systematics has been established and as will be further discussed, $\mu$ and thus $P F$ can both be related to the valence $(v)$ of the filler atom. The valence is the number of electrons taking part in the chemical bonding. As a chemical element, $\mathrm{Yb}$ is divalent $\left(4 \mathrm{f}^{14}(6 \mathrm{~s} 5 \mathrm{~d})^{2}\right)$ but it can be trivalent $\left(4 \mathrm{f}^{13}(6 \mathrm{~s} 5 \mathrm{~d})^{3}\right)$ in compounds such as $\mathrm{Yb}_{2} \mathrm{O}_{3}$ or in a mixed-valent state, as for instance in $\mathrm{YbGaCu}_{4}(v=2.6)^{37}$. In $\mathrm{Yb}_{y} \mathrm{Co}_{4} \mathrm{Sb}_{12}, \mathrm{Yb}$ has been reported to be in a mixedvalent state with $v=2.5$ as determined by X-ray Absorption Spectroscopy (XAS) ${ }^{38}$. This value is rather inconsistent with the mobility $\left(\mu \sim 40 \mathrm{~cm}^{2} \mathrm{~V}^{-1} \mathrm{~s}^{-1}\right)^{24}$ and power factor values $\left(P F \sim 3.5 \mathrm{~mW} \mathrm{~m}^{-1} \mathrm{~K}^{-2}\right){ }^{27}$ found in $\mathrm{Yb}_{y} \mathrm{Co}_{4} \mathrm{Sb}_{12}$, which are rather typical of $\mathrm{Sr}_{y}{ }^{2+} \mathrm{Co}_{4} \mathrm{Sb}_{12}{ }^{39,40}$ and not typical of $\mathrm{Ce}_{y}{ }^{3+} \mathrm{Co}_{4} \mathrm{Sb}_{12}\left(\mu \sim 20 \mathrm{~cm}^{2} \mathrm{~V}^{-1} \mathrm{~s}^{-1}\right.$ and $P F \sim 1 \mathrm{~mW} \mathrm{~m}^{-1} \mathrm{~K}^{-}$

2 in ref. ${ }^{1}$ ). Despite a recent XAS study on $\mathrm{Yb}_{y} \mathrm{Ga}_{z} \mathrm{Co}_{4} \mathrm{Sb}_{12}{ }^{41}$, this mixed valence has never been re-measured, neither confirmed.

In this work, we thus decided to re-examine these open questions. By implementing several experimental techniques, we determined the filling concentration limit of $\mathrm{Yb}$ in $\mathrm{Yb}_{y} \mathrm{Co}_{4} \mathrm{Sb}_{12}$ when synthesized at $1073 \mathrm{~K}$. We measured the valence of $\mathrm{Yb}$ and related it to its low temperature electronic mobility. We also uncovered a spurious chemical instability of $\mathrm{Yb}_{y} \mathrm{Co}_{4} \mathrm{Sb}_{12}$ upon (hand) grinding, which affects the concentration of $\mathrm{Yb}$ in the skutterudite and hence, its thermoelectric properties. By carefully taking this effect into account, we could, in agreement with a simple parabolic band model, reach a high power factor and a high figure of merit at the optimum electron concentration in singlefilled and non-nanostructured $\mathrm{Yb}_{y} \mathrm{Co}_{4} \mathrm{Sb}_{12}$.

\section{Experimental}

Two sets of $\mathrm{Yb}_{y} \mathrm{Co}_{4} \mathrm{Sb}_{12}$ samples were prepared in this work: historically, a first one for the XAS experiments (set1) and then a second one for ytterbium solubility determination 
and transport measurements (set2). Set1 of $\mathrm{Yb}_{y} \mathrm{Co}_{4} \mathrm{Sb}_{12}(y=0.1,0.15,0.20)$ polycrystalline samples was synthesized by melting the elements (Yb 99.9\%, Co 99.99\%, Sb 99.999\%) in stoichiometric quantities at $1423 \mathrm{~K}$ during $24 \mathrm{~h}$ and annealing at $1073 \mathrm{~K}$ during 4 days in vitreous carbon crucibles sealed in a quartz tube under a partial pressure of argon. Set2 of $\mathrm{Yb}_{y} \mathrm{Co}_{4} \mathrm{Sb}_{12}$ polycrystalline samples $(y=0.05,0.1,0.15,0.20,0.25,0.30,0.35,0.40,0.50$, 0.60) were synthesized in a similar way, but the annealing time was longer (7 days) to ensure a better homogeneity of the Yb concentration across the samples. No weight loss could be detected upon weighting. X-ray powder diffraction patterns were collected on each synthesized sample using a Bruker diffractometer (DaVinci, $\mathrm{Cu} \mathrm{K}_{\alpha}$ radiation). The FULLPROF program ${ }^{42}$ was employed for Rietveld refinement in order to obtain the lattice parameters and atomic positions in the various occurring phases as well as their mass fractions.

The alloys of set1 were ball-milled in ceramic vial and balls in a low energy oscillatory grinder. The vial was previously closed in a glove box under argon and the grinder was operated under air during $15 \mathrm{~min}$. The resulting powders were sieved at $10 \mu \mathrm{m}$. Part of the powder was then mixed in an agate mortar with a graphite powder in order to adjust the absorption jump at the X-ray absorption L III edge of ytterbium to $0.1-0.2$ values. These mixtures of powders were cold pressed to obtain a compacted disk suitable for the X-ray absorption spectroscopy (XAS) experiment. The unmixed part of the powder was densified by Spark Plasma Sintering (SPS) in graphite dies and punches for 10 min at 893 K under $50 \mathrm{MPa}$ in a Syntex DR SINTER Lab 515S set-up. To avoid the unexpected partial oxidation of ytterbium (see discussion later), the powders of set2 were thus systematically handled in a glove box under argon: they were manually ground in an agate mortar and then sieved to obtain a powder with particle sizes of less than $36 \mu \mathrm{m}$. This powder was pressed at $300 \mathrm{~K}$ under $160 \mathrm{MPa}$ under argon to minimize air oxidation while 
transferring the sample to the SPS system. This pre-compacted powder was then densified by SPS for $10 \mathrm{~min}$ at $903 \mathrm{~K}$ under $75 \mathrm{MPa}$. Archimede's method indicated that the relative density of every densified sample was systematically larger than $98 \%$. Samples of both set 1 and set 2 densified ingots were powdered again in air and under argon for set1 and set2, respectively, for complementary XRD measurements. Chemical analyses at the nanometer scale were performed on the sintered $\mathrm{Yb}_{0.2} \mathrm{Co}_{4} \mathrm{Sb}_{12}$-set1 sample, using an energy dispersive $\mathrm{X}$ ray (EDX) analysis system placed in a transmission electron microscope (TEM, Tecnai F20). Prior to TEM analyses, the samples were thinned by $\mathrm{Ar}^{+}$ion etching (PIPS, Gatan). The chemical composition of the samples in set2 was determined by Electron Probe Micro Analysis (EPMA, CAMECA SX100).

X-ray absorption spectroscopy was carried out on the SAMBA beamline ${ }^{43}$ at SOLEIL synchrotron source, using a fixed sagitally focusing $\operatorname{Si}(111)$ double crystal monochromator. XANES spectra were recorded in transmission mode, in the 8800-9000 $\mathrm{eV}$ energy range (including $\mathrm{L}_{\mathrm{III}}-\mathrm{Yb}$ edge), with a $0.3 \mathrm{eV}$ resolution in the edge jump, at five different temperatures: 20 K, 70 K, 130 K, 200 K and 300 K. Spectra were normalized using the MAX-Package ${ }^{44}$.

Disk-shaped and bar-shaped samples were cut from the SPS densified ingots with a diamond saw for resistivity, thermal diffusivity and Seebeck coefficient measurements, respectively. The electrical resistivity $(\rho)$ and Seebeck coefficient $(\alpha)$ measurements were carried out between $300 \mathrm{~K}$ and $800 \mathrm{~K}$ using a homemade apparatus ${ }^{45}$. The thermal conductivity $(\lambda)$ was calculated from the measured thermal diffusivity $(a)$, the specific heat $\left(C_{p}\right)$ given by Dulong and Petit's law and the measured density using the relationship $\lambda=a \times C_{p} \times d$. The thermal diffusivity ( $a$ ) was measured by a laser flash method using a Netzsch LFA 427 system. Uncertainties in the electrical resistivity, Seebeck coefficient and thermal conductivity are $8 \%, 6 \%, 11 \%$ respectively ${ }^{46}$ whereas the repeatability is $3 \%$ for 
all these quantities. Room temperature Hall effect measurements were performed in a Physical Properties Measurement System (PPMS, Quantum Design) in AC mode and van der Pauw geometry by varying the magnetic field between $-3 \mathrm{~T}$ and $+3 \mathrm{~T}$. The Hall electron density and Hall electron mobility were defined by $n=-\frac{1}{e R_{H}}$ and $\mu=\frac{R_{H}}{\rho}$ respectively with $R_{H}$ the Hall coefficient.

\section{Results and discussion}

\section{XANES at the Yb LiII edge}

Prior to the XANES experiments, X-ray diffraction analyses of the $\mathrm{Yb}_{y} \mathrm{Co}_{4} \mathrm{Sb}_{12}$ series $(y$ $=0.1,0.15,0.20$, set1) were performed and showed the formation of a skutterudite main phase along with negligible fractions of $\mathrm{Sb}$ and $\mathrm{CoSb}_{2}(0.4 \%$ and $1 \%$ respectively) as secondary phases. Fig. 1a shows the normalized XANES spectra measured in these samples at $300 \mathrm{~K}$. They display two white lines corresponding to the two possible valence states, e.g. divalent $\mathrm{Yb}^{2+}$ and trivalent $\mathrm{Yb}^{3+}$. The deconvolution of the $\mathrm{Yb}$ LIII edge has been performed in a well-established way ${ }^{47}$, using one arctangent and one Lorentzian functions for each valence state according to the formula:

$\mu(E)=\frac{1}{\pi}(3-v)\left[\frac{\pi}{2}+\arctan \left(\frac{E-E_{2}}{W A}\right)\right]+\frac{(3-v) H L}{1+\left(\frac{E-E_{2}}{W L}\right)^{2}}+\frac{1}{\pi}(v-2)\left[\frac{\pi}{2}+\arctan \left(\frac{E-E_{3}}{W A}\right)\right]+\frac{(v-2) H L}{1+\left(\frac{E-E_{3}}{W L}\right)^{2}}(1)$

The parameter $v$ is the ytterbium valence, 3-v and $v-2$ are the weight of the $\mathrm{Yb}^{2+}$ and $\mathrm{Yb}^{3+}$ electronic configuration respectively. The parameters $\mathrm{E}_{2}$ and $\mathrm{E}_{3}$ are the edge position for the $\mathrm{Yb}^{2+}$ and $\mathrm{Yb}^{3+}$ configurations, both held fixed at values independent on temperature and sample $\left(\mathrm{E}_{2}=8941.0 \mathrm{eV}\right.$ and $\left.\mathrm{E}_{3}=8949.3 \mathrm{eV}\right) . \mathrm{WA}=2.7 \mathrm{eV}$ and $\mathrm{WL}=2.9 \mathrm{eV}$ are the widths of the arctangent and Lorentzian functions, respectively. Both are only dependent on the experimental resolution while HL, the magnitude of the Lorentzian, slightly varies with $y$. An example of such a fit is shown in Fig. $1 \mathrm{~b}$ for $\mathrm{Yb}_{0.20} \mathrm{Co}_{4} \mathrm{Sb}_{12}$. The valence of $\mathrm{Yb}$ at 
$300 \mathrm{~K}$ is $2.20,2.24$ and 2.14 in $\mathrm{Yb}_{0.10} \mathrm{Co}_{4} \mathrm{Sb}_{12}, \mathrm{Yb}_{0.15} \mathrm{Co}_{4} \mathrm{Sb}_{12}$ and in $\mathrm{Yb}_{0.20} \mathrm{Co}_{4} \mathrm{Sb}_{12}$ respectively, indicating no monotonous variation with the $\mathrm{Yb}$ concentration and therefore no dependence on this parameter. Measurements of the Yb LIII edge as a function of temperature in all three samples revealed random variations of the valence smaller than the uncertainty $( \pm 0.02)$. The valence is thus temperature-independent and this makes highly improbable the possibility of a "fluctuating" non-integral valence for $\mathrm{Yb}$. It could also originate from two different crystallographic sites in $\mathrm{Yb}_{y} \mathrm{Co}_{4} \mathrm{Sb}_{12}$ but it is incompatible with the $\mathrm{LaFe}_{4} \mathrm{P}_{12}$ structure type, which bears only one $\mathrm{Yb}$ site (the $2 \mathrm{a}$ site, at the center of the $\mathrm{Sb}$ icosahedron). The presence of divalent $\mathrm{Yb}$ in $\mathrm{Yb}_{y} \mathrm{Co}_{4} \mathrm{Sb}_{12}$ and of trivalent $\mathrm{Yb}$ in another phase such as $\mathrm{Yb}_{2} \mathrm{O}_{3}$ arising from a spurious and partial oxidation under air of ytterbium from the skutterudite could be a better scenario, consistent with both the independence with temperature and Yb concentration. It is assumed that this oxidation would have occurred during the mechanical milling stage, which was performed to obtain fine powders for the XAS experiment. We will discuss in the following paragraph upon other experimental data consistent with this scenario.

\section{Complementary experiences and discussion on the Yb valence}

Electrical resistivity (see supplementary information Fig. S1) measured after the XAS experiment in the $\mathrm{Yb}_{y} \mathrm{Co}_{4} \mathrm{Sb}_{12}$ samples $(y=0.10,0.15,0.20$, set1) from 300 to $800 \mathrm{~K}$ displayed a semi-conducting behavior in all three samples whereas a metallic behavior was expected in every case since these samples should be degenerate $n$-type semiconductors ${ }^{26}$. This is indicative of a smaller electron concentration in $\mathrm{Yb}_{y} \mathrm{Co}_{4} \mathrm{Sb}_{12}$, arising from a decrease of the donor concentration, e.g. Yb in the skutterudite upon mechanical milling. A more direct evidence of the variation of the $\mathrm{Yb}$ concentration in the skutterudite upon milling is provided by changes in lattice parameters recorded on non- 
milled and after the XAS experiments samples. It can easily be noticed in Table I that the lattice parameter systematically decreases in the $\mathrm{Yb}_{y} \mathrm{Co}_{4} \mathrm{Sb}_{12}$ samples upon the low energy mechanical milling. Based on the dependence of the lattice parameter on $y$ shown in Fig. 4, an approximate effective reduced $\mathrm{Yb}$ concentration can be derived and reported in Table I. The most probable scenario for this $\mathrm{Yb}$ concentration reduction in the skutterudite is the extraction of ytterbium from the skutterudite caused by a combination of grinding and oxidation by air, leading to $(\delta / 2) \mathrm{Yb}_{2} \mathrm{O}_{3}+\mathrm{Yb}_{y-\delta} \mathrm{Co}_{4} \mathrm{Sb}_{12} . \mathrm{Yb}_{2} \mathrm{O}_{3}$ could nonetheless not be detected in the XRD patterns. We hence carried out transmission electron microscopy (TEM) at a mesoscopic scale on the $y=0.20$ sintered sample. The scanning transmission electron (STEM) image and elemental X-ray images shown in Fig. 2 were recorded close to a sample edge. Twenty nanometers $\mathrm{YbO}_{\mathrm{x}}$ precipitates, most probably with $\mathrm{Yb}_{2} \mathrm{O}_{3}$ composition, can be observed in these images. Their nanometric size explains why XRD was unable to detect them. More importantly, their occurrence confirms the scenario inferred from the XAS, resistivity and XRD data. The extraction of the filler atom from a $n$-type skutterudite upon grinding has indeed already been reported in $\operatorname{In}_{y} \mathrm{Co}_{4} \mathrm{Sb}_{12}{ }^{10,48}$. Currently, it is nonetheless not clear whether grinding by itself is the driving force for extracting $\mathrm{Yb}$ from the skutterudite or if it is oxidation enhanced by grinding which is responsible for this effect. Anyway, from all these data, it can be concluded that the valence of $\mathrm{Yb}$ is equal to 2 in $\mathrm{Yb}_{y} \mathrm{Co}_{4} \mathrm{Sb}_{12}(y=0.10,0.15,0.20)$, independent on temperature and $\mathrm{Yb}$ concentration while the trivalent contribution observed in the present spectra arises from $\mathrm{Yb}_{2} \mathrm{O}_{3}$.

\section{Filling concentration limit of $\mathrm{Yb}$ in $\mathrm{Yb}_{y} \mathrm{Co}_{4} \mathrm{Sb}_{12}$}

Because of the extraction-oxidation of ytterbium from the skutterudites observed during low energy grinding, we have thereafter systematically hand-ground the samples 
in a glove box, under argon atmosphere. As will be further discussed, no change between the nominal and the actual $\mathrm{Yb}$ concentration could then be detected. The X-ray diffraction patterns of the $\mathrm{Yb}_{y} \mathrm{Co}_{4} \mathrm{Sb}_{12}$ samples $(y=0.05,0.1,0.15,0.20,0.25,0.30,0.35,0.400 .50$ and 0.60 , set2) showed the formation of a skutterudite phase accompanied by $0.4 \%$ of $\mathrm{Sb}$ and $1 \%$ of $\mathrm{CoSb}_{2}$ (fractions similar to those in samples in set 1 ), up to $y=0.30$. A refinement of the X-ray pattern of $\mathrm{Yb}_{0.10} \mathrm{Co}_{4} \mathrm{Sb}_{12}\left(\mathrm{R}_{w p}=3.1 \%\right.$ and $\left.\mathrm{R}_{\mathrm{B}}=11.3 \%\right)$ is displayed in Fig. 3 as an example. The $0.4 \% \mathrm{Sb}$ and $1 \% \mathrm{CoSb}_{2}$ phases cannot be seen at the scale of the figure, underlining that their fractions are very small. The effect on the thermoelectric properties of these minutes amount of $\mathrm{Sb}$ and $\mathrm{CoSb}_{2}$ can safely be neglected for $y \leq 0.3$, in agreement with previous reports ${ }^{25,26}$. Beyond this nominal concentration, not only $\mathrm{Sb}, \mathrm{CoSb}$ but also $\mathrm{YbSb}_{2}$ could be observed as secondary phases, in consistency with previous experimental reports 25, 26. Based on density functional theory, a recent theoretical work ${ }^{49}$ also concluded, after implementing minor corrections to the ab-initio calculated energies of formation, that $\mathrm{Yb}_{y} \mathrm{Co}_{4} \mathrm{Sb}_{12}$ decomposes into semi-conducting ${ }^{50} \mathrm{CoSb}_{2}$, metallic ${ }^{51} \mathrm{YbSb}_{2}$ and semi-conducting $\mathrm{CoSb}_{3}$. For $y>0.3$, the fractions of $\mathrm{YbSb}_{2}, \mathrm{CoSb}_{2}$ and $\mathrm{Sb}$ increased with $y$ from $0.6 \%, 1 \%, 0.4 \%$ in $\mathrm{Yb}_{0.35} \mathrm{Co}_{4} \mathrm{Sb}_{12}$ to 4\%, 3 \%, 1 \% in $\mathrm{Yb}_{0.60} \mathrm{Co}_{4} \mathrm{Sb}_{12}$ respectively (see also backscattered electron images in supplementary information). These larger fractions of secondary phase can affect the thermoelectric properties of $\mathrm{Yb}_{y} \mathrm{Co}_{4} \mathrm{Sb}_{12}$, as previously reported in ref. ${ }^{26}$ and as will also be further discussed. Fig. 4 shows the variation of the lattice parameter $(a)$ as a function of the nominal ytterbium concentration, compared to data from the literature 24-26,52. The lattice parameter linearly increases from $a=9.036 \AA$ up to the saturation value $a=9.075 \AA$ with a slope slightly larger than in the literature, indicating a slightly larger effective filling concentration in our samples for a given nominal concentration. The lattice parameter $a=9.075 \AA$ doesn't vary anymore for $y \geq 0.4 \mathrm{~mol} /$ (formula unit = f.u.), suggesting that the solubility or filling 
concentration limit of $\mathrm{Yb}$ in the skutterudite at $1073 \mathrm{~K}$ is close to this value. A linear fit to the data yields $y_{\text {lim }}=0.41 \pm 0.02 \mathrm{~mol} /$ f.u.. The EPMA data reported in Table II highlights one important result of the present work: the effective Yb concentration is equal to the nominal concentration for $y \leq 0.40$. This result is expected for $y \leq 0.30$ since no secondary phase containing $\mathrm{Yb}$ could be detected. It is more surprising for $0.30<y \leq 0.40$ since $\mathrm{YbSb}_{2}$ is observed as a secondary phase. Firstly, Grytsiv et al. previously reported 53 that in $\mathrm{In}_{y} \mathrm{Co}_{4} \mathrm{Sb}_{12}$, the appearance for $y(\operatorname{In})=0.10$ of $\operatorname{InSb}$ as a secondary phase containing In did not imply that the FCL of In is reached at the former concentration. They indeed carefully determined, implementing several techniques, that $y_{\lim }(\mathrm{In})=0.22$ in $\operatorname{In}_{y} \mathrm{Co}_{4} \mathrm{Sb}_{12}$, upon synthesizing at $973 \mathrm{~K}$. Similarly, increasing $y$ still increases the $\mathrm{Yb}$-filling concentration in the skutterudite beyond 0.3. Secondly, despite the increasing fraction of YbSb2 with $y$, the Yb-filling concentration remains equal to the nominal concentration for $0.30<y \leq 0.40$, due to the increasing $\mathrm{CoSb}_{2}$ and $\mathrm{Sb}$ fractions, balancing $\mathrm{YbSb}_{2}$. In the literature $24,26,52$, the effective $\mathrm{Yb}$ concentration measured after densification is systematically smaller than the nominal one. As already discussed in the previous paragraph, this effect is likely to arise from the oxidation of ytterbium upon annealing directly in quartz tube the skutterudite or grinding it in air into the fine powder required for sintering. The EPMA data confirm that the Yb FCL is ylim $=0.41 \pm 0.02 \mathrm{~mol} /$ f.u. in the skutterudite. Finally, this value is also confirmed by the Hall electron concentration $n$ versus $y$ curve displayed in Fig. 5 (these Hall data will be further commented in the next section). For $y=0.4, n$ saturates in agreement with the saturation of the ytterbium concentration in the skutterudite observed by the other techniques. This measured FCL ylim $=0.41$ is in fair agreement with the FCL $y_{\text {lim }}=0.3$ theoretically predicted 29,30 . Tang et al. ${ }^{25}$ showed that the FCL in $\mathrm{Yb}_{y} \mathrm{Co}_{4} \mathrm{Sb}_{12}$ increases with the synthesis temperature from $y_{\text {lim }} \sim 0.1$ at $773 \mathrm{~K}$ to $y_{\text {lim }} \sim 0.5$ at $1073 \mathrm{~K}$. It explains why in the literature, the reported FCL is $y_{\text {lim }}=0.26-0.29$ when 
synthesized at $993 \mathrm{~K}^{24,26,31}$ and why $y_{\lim }=0.41$ at $1073 \mathrm{~K}$ can be found in the present work. Nonetheless, there is a $+20 \%$ discrepancy between the value $y_{\text {lim }}=0.48$ determined from EPMA data in samples synthesized at $1073 \mathrm{~K}$ by authors of ref. ${ }^{25}$ and the present value. Surprisingly, a sample is reported in ref. 25 with an EPMA composition $\mathrm{Yb}_{0.30} \mathrm{Co}_{4} \mathrm{Sb}_{12},+20 \%$ larger than its nominal composition $\mathrm{Yb}_{0.25} \mathrm{Co}_{4} \mathrm{Sb}_{12}$. Dividing the ytterbium concentrations reported in ref. ${ }^{25}$ by 1.2 and plotting again the reported lattice parameter versus these normalized concentrations leads to a very good agreement with the present data, both sets saturating at $a=9.075 \AA$, as shown in the Supplementary Material (Fig. S3). Thus, ylim $=0.41 \pm 0.02 \mathrm{~mol} /$ f.u. for a temperature synthesis of $1073 \mathrm{~K}$ can be considered as the critically assessed FCL of ytterbium in $\mathrm{Yb}_{y} \mathrm{Co}_{4} \mathrm{Sb}_{12}$.

\section{Transport properties in $\mathrm{Yb}_{y} \mathrm{Co}_{4} \mathrm{Sb}_{12}$}

\section{Electronic transport properties at room temperature}

The electronic transport properties of $\mathrm{Yb}_{y} \mathrm{Co}_{4} \mathrm{Sb}_{12}$ of set2 samples at room temperature are reported in Table II, Figs 5, 6a, and 6b. From table II, it can be seen that the electrical resistivity and the absolute value of the Seebeck coefficient decrease, in agreement with the variations of the electron concentration and the ytterbium concentration until the $\mathrm{Yb}$ FCL is reached. In consistency with the electron donor character of $\mathrm{Yb}$ and its solubility limit, the electron density $n$ increases with the $\mathrm{Yb}$ concentration $y$ until the FCL $y_{\text {lim }}=0.41$ is reached, afterwards it is saturating (Fig. 5). The increase is linear with $y$, following a first slope between $y=0$ and $y=0.33 \pm 0.02$ and a second slope between $y=0.33 \pm 0.02$ and the FCL. To better understand this behavior, the $n(x)$ data for $\mathrm{Co}_{1-x} \mathrm{Ni}_{x} \mathrm{Sb}_{3}$ (extracted from ref. ${ }^{35}$ ) are plotted on the same graph as the $\mathrm{Yb}_{y} \mathrm{Co}_{4} \mathrm{Sb}_{12}$ data after multiplying the $x$ values by a factor adjusted at the value 3.45 to superimpose both datasets. The fact that this adjusted factor is smaller than 4 reflects the 
better $n$-type doping efficiency of $\mathrm{Ni}$ when compared to Yb. For both series, the breakpoint separating the two slopes is reached for a common electron concentration $n=7.5 \times 10^{20}$ $\mathrm{cm}^{-3}$, showing that this effect does not depend on the nature of the dopant. It rather arises from a feature intrinsic to the electronic structure in $\mathrm{CoSb}_{3}$ that could most likely be the completion of one or several of the conduction bands in $\mathrm{CoSb}_{3}$ upon electron filling. For $\mathrm{Co}_{1-x} \mathrm{Ni}_{x} \mathrm{Sb}_{3}$, the breakpoint also coincides with the solubility limit of $\mathrm{Ni}$ in $\mathrm{CoSb}_{3}(x=0.09)$, indicating that electronic effects could dominate over the Co / Ni atomic size differences to determine this limit. For $\mathrm{Yb}_{y} \mathrm{Co}_{4} \mathrm{Sb}_{12}$, it does not coincide with the solubility limit of $\mathrm{Yb}$ but rather to a change in the contents and nature of the secondary phases: the quantities of $\mathrm{Sb}, \mathrm{CoSb}_{2}$ and more specifically $\mathrm{YbSb}_{2}$ increase with $y$ beyond 0.33 . Again, the different chemical reactivity of the dopant towards $\mathrm{CoSb}_{3}$ leads to a change in the electronic structure of $\mathrm{CoSb}_{3}$ upon electron filling. Together with $\mathrm{Yb}_{y} \mathrm{Co}_{4} \mathrm{Sb}_{12}$, the secondary phases may contribute to the Hall signal for $0.33 \leq y \leq 0.42$. It is however difficult to weight their respective contribution: the observed strong increase of $n(y)$ is likely to be at least partially extrinsic. For $y \leq 0.33$, the contribution to the Hall signal of the minute amounts of secondary phases can be neglected. The slope of this segment is thus intrinsic and amounts to $2.6 \times 10^{21}$ electrons / mol(Yb), reflecting a stronger doping efficiency for $\mathrm{Yb}$ than for instance In, which displays a doping efficiency of $0.7 \times 10^{21}$ electrons / mol(In) 10. A direct comparison of these $n(y)$ data to previously reported data on $\mathrm{Yb}_{y} \mathrm{Co}_{4} \mathrm{Sb}_{12} 24,27$ shows that for a given $y$, the current $n(y)$ value is systematically larger than those previously published. It may probably arise from an over- estimation of their actual $\mathrm{Yb}$ concentration. Indeed, if we multiply their nominal $y$ by 0.5 and 0.8 respectively, the data of Yang et al. ${ }^{24,27}$ and Xiong et al. ${ }^{24,27}$ follow our data (Fig. 5). Direct comparison with the more recent and complete work reported in the Supplementary Information of ref. 34 was 
prevented by inconsistencies in the data (table S2 and figures) presented in this last reference.

As already mentioned in the introduction, the maximum power factor has been reported to be experimentally achieved for $n \sim 3-4 \times 10^{20} \mathrm{~cm}^{-3} 15,24,25,27,34$ and not for the theoretically predicted value $n_{\text {opt }}=2 \times 10^{20} \mathrm{~cm}^{-3} 10,34$. To better understand this discrepancy, we compared our experimental power factor data to calculated values based on a single parabolic band model with electrons parameterized by a single averaged density of states effective mass $m^{*}$ and scattered by acoustic phonons $24,25,54$. According to this model, which has already proven its efficiency in the cases of $\mathrm{Co}_{1-x} \mathrm{Pd}_{x} \mathrm{Sb}_{3}{ }^{35}$ and $\operatorname{In}_{y} \mathrm{Co}_{4} \mathrm{Sb}_{12}{ }^{10}$, the Seebeck coefficient $(\alpha)$, the electrical conductivity $(\sigma)$ and the electron density $(n)$ are related to the reduced chemical potential $\left(\eta=\mu / k_{B} T\right)$ by the following equations:

$$
\begin{aligned}
& \alpha=-\frac{k_{B}}{e}\left(2 \frac{F_{1}(\eta)}{F_{2}(\eta)}-\eta\right)(2) \\
& n=4 \pi\left(\frac{2 m^{*} k_{B} T}{h^{2}}\right)^{\frac{3}{2}} F_{\frac{1}{2}}(\eta)(3) \\
& \sigma=\frac{8 \pi e^{2} \tau_{0}}{3}\left(\frac{2}{h^{2}}\right)^{\frac{3}{2}}\left(m^{*}\right)^{\frac{1}{2}} k_{B} T F_{0}(\eta)(4)
\end{aligned}
$$

where the $F_{n}$ are Fermi integrals (see ref. 55 for a definition), $k_{B}$ the Boltzman constant, $e$ the electron charge, $\mathrm{h}$ Planck's constant and $\tau_{0}$ the pre-factor in the expression describing the energy $\varepsilon$ dependence of the relaxation time:

$\tau=\tau_{0} \varepsilon^{-1 / 2}(5)$

Before calculating the power factor, a value of the density of states effective mass has to be derived from a plot of the experimental Seebeck coefficient versus electron density data $(n)$ - the so-called Pisarenko plot - as shown in Fig. 6a. Given the possibility of a contribution of the secondary phases to the Hall signal when $n>7.5 \times 10^{20} \mathrm{~cm}^{-3}$ (see Fig. 
5), the four samples with $y>0.33$ were not taken into account for this part of the investigation. Samples with electron density smaller than $1.5 \times 10^{20} \mathrm{~cm}^{-3}$ fall on the $\mathrm{m}^{*}=$ $2.7 \pm 0.2 m_{e}$ ( $m_{e}$ is the bare electron mass) theoretical curve whereas those with electron density larger than $1.5 \times 10^{20} \mathrm{~cm}^{-3}$ fall on the $m^{*}=3.4 \pm 0.2 m_{e}$ curve. The increase of the density of states effective mass with electron density in $n$-type skutterudites has already been ascribed to the progressive filling of several conduction bands either degenerate or very close in energy 33,34 . The intermediate value $m^{*}=3.2 m_{e}$ was hence chosen to calculate the electrical conductivity and power factor $P F=\alpha^{2} \sigma$ at $300 \mathrm{~K}$ in the entire range of electron densities. To adjust the calculations to $\mu_{e}=45.5 \mathrm{~cm}^{2} \mathrm{~V}^{-1} \mathrm{~s}^{-1}$ when $n=3.9 \times 10^{20}$ $\mathrm{cm}^{-3}$, the experimental value of mobility found in $\mathrm{Yb}_{0.20} \mathrm{Co}_{4} \mathrm{Sb}_{12}$, the parameter $\tau_{0}$ was calculated to be equal to $\tau_{0}=0.9 \times 10^{-23} \mathrm{~J}^{1 / 2} \mathrm{~s}$. The calculated and experimental power factors are presented in Fig. 6b, highlighting a very good agreement. A noticeable maximum $P F_{\max }=4.0-4.2 \mathrm{~mW} \mathrm{~m}^{-1} \mathrm{~K}^{-2}$ is reached when the electron density is $n_{\text {opt }}=1.8 \pm$ $0.2 \times 10^{20} \mathrm{~cm}^{-3}$, the value not only theoretically predicted ${ }^{34}$ but also experimentally observed in $\operatorname{In}_{y} \mathrm{Co}_{4} \mathrm{Sb}_{12}{ }^{10}$. Again, it can be surmised that the partial oxidation of ytterbium upon grinding in air before sintering leads to smaller effective ytterbium concentration in the $\mathrm{Yb}_{y} \mathrm{Co}_{4} \mathrm{Sb}_{12}$ samples where the optimum electron density has been reported to be $n_{\text {opt }}$ $=3-4 \times 10^{20} \mathrm{~cm}^{-3}$, based only on experiments $15,24,25,27,34$. For the first time, experiment and theory both agree on the optimum electron concentration necessary for achieving the maximum power factor in $\mathrm{Yb}_{y} \mathrm{Co}_{4} \mathrm{Sb}_{12}$.

\section{Electronic transport properties as a function of temperature}

\section{Electronic mobility at low temperature}

As already reviewed in the introduction, the electronic transport properties of $\mathrm{Yb}_{y} \mathrm{Co}_{4} \mathrm{Sb}_{12}$ reported in the literature ${ }^{24,27}$ are rather in agreement with the divalent 
character of $\mathrm{Yb}$, and are very close to those obtained with divalent alcaline earth based skutterudites such as $\mathrm{Sr}_{y} \mathrm{Co}_{4} \mathrm{Sb}_{12}{ }^{39,40}$ and $\mathrm{Ba}_{y} \mathrm{Co}_{4} \mathrm{Sb}_{12}$ 5, 30. To better establish the correlation between the valence and the electron transport properties, the Hall electronic mobility $(\mu)$ of $\mathrm{Yb}_{0.05} \mathrm{Co}_{4} \mathrm{Sb}_{12}$ (set2) was measured as a function of temperature in the range $5-300 \mathrm{~K}$ and compared in Fig. 7 to other $A_{y} \mathrm{Co}_{4} \mathrm{Sb}_{12}$ skutterudites data extracted from the literature ${ }^{32,56}$. In the $150-300 \mathrm{~K}$ temperature range, $\mu$ displays the well-known $\mathrm{T}^{-3 / 2}$ behavior 57 , characteristic of electron scattering by the acoustic phonons $24,32,57$. At low temperature, between 5 and $20 \mathrm{~K}, \mu$ is temperature-independent, as expected in the case of electrons predominantly scattered by ionized impurities in a degenerate semiconductor ${ }^{58,59}$. From Fig. 7, it can be seen that, at low temperature, the mobility is highly dependent on the valence of the filler atom $A$ and decreases as the valence increases: at $10 \mathrm{~K}, \mu \sim 2400 \mathrm{~V} \mathrm{~cm}^{-2} \mathrm{~s}^{-1}$ in monovalent $\operatorname{In}_{y}{ }^{1+} \operatorname{Co}_{4} \mathrm{Sb}_{12}(A=\mathrm{In}){ }^{56}, \mu \sim 1200 \mathrm{~V} \mathrm{~cm}^{-2} \mathrm{~s}^{-1}$ in monovalent $\mathrm{Na}_{y}{ }^{1+} \mathrm{Co}_{4} \mathrm{Sb}_{12}(A=\mathrm{Na}){ }^{32}, \mu \sim 600 \mathrm{~V} \mathrm{~cm}^{-2} \mathrm{~s}^{-1}$ in divalent $\mathrm{Ba}_{y}{ }^{2+} \mathrm{Co}_{4} \mathrm{Sb}_{12}{ }^{32}, \mu \sim$ $700 \mathrm{~V} \mathrm{~cm}^{-2} \mathrm{~s}^{-1}$ in divalent $\mathrm{Yb}_{y}{ }^{2+} \mathrm{Co}_{4} \mathrm{Sb}_{12}$ (this work) and $\mu \sim 220 \mathrm{~V} \mathrm{~cm}^{-2} \mathrm{~s}^{-1}$ in trivalent $\mathrm{Nd}_{y}{ }^{3+} \mathrm{Co}_{4} \mathrm{Sb}_{12}{ }^{56}$. According to Dingle (and others), the mobility of electrons scattered by ionized impurities varies like $\frac{1}{v^{2}}$ with $v$ the valence of the electron donor atoms 58,59 . The low temperature values of mobility are thus plotted as a function of $\frac{1}{v^{2}}$ in the inset of Fig. 7, as well as a linear fit to the data. The $\mathrm{Na}_{0.36} \mathrm{Co}_{4} \mathrm{Sb}_{12}$ compound was discarded from the fit because of the high reactivity of sodium towards air $\left(\mathrm{O}_{2}\right.$ and moisture), probably giving rise at the grinding stage to secondary phases affecting its electronic transport properties. The good quality of the linear fit indicates that $\mu \propto \frac{1}{v^{2}}$ at low temperature. Quantitative extrapolation to higher temperature cannot be performed but the trend remains the same. As the electronic effective mass is independent on the nature of the filler atom ${ }^{32}$, the fit explains why the power factor at room temperature varies like $P F\left(A^{3+}\right)<P F\left(A^{2+}\right)<\operatorname{PF}\left(A^{1+}\right)$ 
in the optimized $A_{y} \mathrm{Co}_{4} \mathrm{Sb}_{12}$. Furthermore, the larger $Z T$ values displayed by $\operatorname{In}^{1+}$ and $\mathrm{Yb}^{2+}$ partially filled skutterudites can be at posteriori explained by the combined effect of the previous valence-dependent $P F$ s and the low values of lattice thermal conductivities achieved in heavy-atom filled skutterudites.

\section{Seebeck coefficient, resistivity and power factor at high temperature}

For each measured sample in the set2 series, the variation as a function of temperature of the Seebeck coefficient (Fig. 8.a), resistivity (Fig. 8.b.), and power factor (Fig. 8.c) is typical of the behavior of a degenerate $n$-type semiconductor, with activation of the minority carriers at a temperature that increases as expected with the electron concentration: it is around $600 \mathrm{~K}$ in $\mathrm{Yb}_{0.05} \mathrm{Co}_{4} \mathrm{Sb}_{12}\left(n=0.46 \times 10^{20} \mathrm{~cm}^{-3}\right)$ and beyond $800 \mathrm{~K}$ in $\mathrm{Yb}_{0.4} \mathrm{Co}_{4} \mathrm{Sb}_{12}\left(n=14.7 \times 10^{20} \mathrm{~cm}^{-3}\right)$. At any temperature, all the variations of the Seebeck coefficient and resistivity from sample to sample are consistent with the variations already discussed of both these quantities at $300 \mathrm{~K}$ in the previous paragraphs. The same remark applies to the power factor except for the $y=0.05$ and 0.10 samples due to the lower temperature of activation of their minority carriers. The maximum value of the power factor $P F_{\max }=5.5 \mathrm{~mW} \mathrm{~m}^{-1} \mathrm{~K}^{-2}$ is reached at $650 \mathrm{~K}^{\text {in }} \mathrm{Yb}_{0.15} \mathrm{Co}_{4} \mathrm{Sb}_{12}$ and at $700 \mathrm{~K}$ in $\mathrm{Yb}_{0.20} \mathrm{Co}_{4} \mathrm{Sb}_{12}$. This value is in good agreement with the values reported in the literature but obtained for larger nominal Yb concentrations: $P F_{\max }=5.2 \mathrm{~mW} \mathrm{~m}^{-1} \mathrm{~K}^{-2}$ in ref. ${ }^{24}$ for $\mathrm{Yb}_{0.26} \mathrm{Co}_{4} \mathrm{Sb}_{12}, P F_{\max }=5.1 \mathrm{~mW} \mathrm{~m}{ }^{-1} \mathrm{~K}^{-2}$ in ref. ${ }^{25}$ and $P F_{\max }=5.5 \mathrm{~mW} \mathrm{~m}^{-1} \mathrm{~K}^{-2}$ in ref. ${ }^{26}$ for $\mathrm{Yb}_{0.30} \mathrm{Co}_{4} \mathrm{Sb}_{12}$.

\section{Thermal conductivity at high temperature}

The lattice $\left(\lambda_{L}\right)$ and total thermal conductivity $(\lambda)$ are shown as a function of temperature in Fig. 9a and $9 \mathrm{~b}$ for every $\mathrm{Yb}_{y} \mathrm{Co}_{4} \mathrm{Sb}_{12}$ sample. The lattice thermal 
conductivity was obtained by subtraction of the electronic contribution $\left(\lambda_{E}\right)$ from the total thermal conductivity using the Wiedmann-Franz law. To estimate the electronic contribution, the Lorenz number $(L)$ was calculated as a function of the reduced chemical potential and temperature, using the same single parabolic band model and the same parameters ( $m^{*}=3.2 m_{e}$ and $\tau=\tau_{0} \varepsilon^{-1 / 2}$ ) as described previously. $L$ is related to $\eta$ by the following expression 55 :

$$
L=\left(\frac{k_{B}}{e}\right)^{2} \frac{3 F_{0}(\eta) F_{2}(\eta)-4 F_{1}(\eta)^{2}}{F_{0}(\eta)^{2}}(6) .
$$

Values of calculated $L(\eta, T)$ are reported in Table SI of the Supplementary Material. In each sample, due to increasing phonon-phonon interactions, the lattice thermal conductivity decreases with temperature until the bipolar effect sets in, at a temperature that increases with the electron or ytterbium concentration. At a given temperature below $550 \mathrm{~K}$, it can also easily be noticed that the lattice thermal conductivity monotonously decreases as a function of the ytterbium concentration until $y=0.35$. For $y \geq 0.40$, the lattice thermal conductivity increases with $y$, most likely due to the larger thermal conductivity of the secondary phases $\left(\mathrm{Sb}, \mathrm{CoSb}_{2}, \mathrm{YbSb}_{2}\right)$, whose fractions increase beyond $y=0.33$. This decrease of $\lambda_{L}(y)$ has of course already been reported and commented numerous times ${ }^{2}$, 24-27. It has been ascribed to the number, increasing with $y$, of low-energy and dispersionless phonons ${ }^{11,12}$, which scatter the acoustic phonons. The value $\lambda_{L}=1.3 \mathrm{~W} \mathrm{~m}^{-}$ ${ }^{1} \mathrm{~K}^{-1}$ observed here in $\mathrm{Yb}_{0.35} \mathrm{Co}_{4} \mathrm{Sb}_{12}$, which is the most $\mathrm{Yb}$-filled sample with only very small fractions of secondary phases, is significantly smaller than $\lambda_{L}=1.7 \mathrm{~W} \mathrm{~m}^{-1} \mathrm{~K}^{-1}$ usually reported in the literature for the most filled samples (nominal $y$ ranging from 0.26 to 0.5 ) 24-27. This fact simply reflects, as already discussed in previous paragraphs, the larger effective filling concentration - equal here to the nominal concentration - of the current $\mathrm{Yb}_{0.35} \mathrm{Co}_{4} \mathrm{Sb}_{12}$ sample. The value $\lambda_{L}=1.7 \mathrm{~W} \mathrm{~m}^{-1} \mathrm{~K}^{-1}$ actually corresponds to the $y=0.25$ - 
0.30 samples of the present study. Nonetheless, $\lambda_{L}=1.3 \mathrm{~W} \mathrm{~m}^{-1} \mathrm{~K}^{-1}$ is still larger than $\lambda_{L}=$

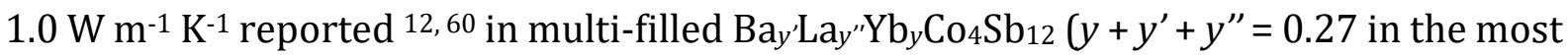
filled sample), confirming the efficiency of multi-filling to further decrease the lattice thermal conductivity.

In Fig. 9b, the total thermal conductivity in $\mathrm{Yb}_{y} \mathrm{Co}_{4} \mathrm{Sb}_{12}$ displays variations with temperature similar to those of the lattice thermal conductivity: an expected decrease with temperature until the bipolar effect becomes important and leads to an increase of the total thermal conductivity. However, from sample to sample the total thermal conductivity does not strictly mimic the lattice thermal conductivity behavior. At $300 \mathrm{~K}$, it decreases with the ytterbium concentration not until $y=0.35$ but until $y=0.15$, where it saturates at the value $\lambda=3.6 \mathrm{~W} \mathrm{~m}^{-1} \mathrm{~K}^{-1}$. Coincidently, between $y=0.15$ and $y=0.35$ the decrease of lattice thermal conductivity with $y$ is exactly compensated - within uncertainty - by the increase of electronic thermal conductivity. For $y>0.25$, the electronic thermal conductivity becomes larger than the lattice thermal conductivity and for $y>0.35$, not only $\lambda_{E}$ but also $\lambda_{L}$ increases with $y$ due to the contribution from the secondary phases: this leads to $\lambda \geq 4.0 \mathrm{~W} \mathrm{~m}^{-1} \mathrm{~K}^{-1}$ values. In $\mathrm{Yb}_{y} \mathrm{Co}_{4} \mathrm{Sb}_{12}$, due to a combination of factors, the total thermal conductivity as function of $y$ is thus not minimum at the FCL of ytterbium but at $y=0.15$, a value well "inside" the homogeneity range, not only when the synthesis is implemented at $1073 \mathrm{~K}$ but also at a smaller temperature like $873 \mathrm{~K}$ where the FCL $=$ 0.25 after correction by $20 \%$ of the value reported in ref. ${ }^{25}$. The FCL is thus not a parameter as a critical as it has been considered in the past 29,30 to optimize the thermoelectric properties in $\mathrm{Yb}_{y} \mathrm{Co}_{4} \mathrm{Sb}_{12}$.

\section{Figure of merit at high temperature}


The dimensionless figure of merit ZT is displayed as a function of temperature in Fig. 10 for all the $\mathrm{Yb}_{y} \mathrm{Co}_{4} \mathrm{Sb}_{12}$ samples. The best values of $Z T$ are observed in $\mathrm{Yb}_{0.15} \mathrm{Co}_{4} \mathrm{Sb}_{12}$ with a maximum value $Z T_{\max }=1.4$ at $750 \mathrm{~K}$ and an average value $Z T_{a v}=0.95$ over the temperature range $300-800 \mathrm{~K}$, which is quite remarkable. Within uncertainty on the figure of merit ( $\sim 15 \%$ according to ref. $\left.{ }^{26}\right)$, a similar value of $Z T_{\max }$ has already been reported in $\mathrm{Yb}_{y} \mathrm{Co}_{4} \mathrm{Sb}_{12}{ }^{26}$ but it is the first time that it is obtained for such a small concentration of ytterbium. Usually, $y=0.25-0.3$ are necessary to reach $Z T_{\max }=1.3-1.5$ 24-26,34. Reaching this high ZT with such a small Yb concentration compared to previous reports is also very promising for the applications, since $\mathrm{Yb}$ is the most expensive element among the three. This result has been achieved thanks to our efforts to finely control the effective concentration of ytterbium and to make it equal to the nominal one. For $y<0.15$, $Z T$ increases with $y$, driven by the decrease of the lattice and total thermal conductivity. For $y>0.15, Z T$ decreases with $y$, driven by the evolution of the power factor. It can finally be noticed that in $\mathrm{Yb}_{y} \mathrm{Co}_{4} \mathrm{Sb}_{12}$, for the broad range of ytterbium concentrations $0.10 \leq y$ $\leq 0.35, Z T_{\max }$ and $Z T_{a v}$ remarkably exceeds 1.0 and 0.7 respectively.

\section{Summary}

By a combination of XANES, XRD and TEM data, ytterbium was shown to display a valence of 2 in $\mathrm{Yb}_{y} \mathrm{Co}_{4} \mathrm{Sb}_{12}(0.10 \leq y \leq 0.20)$, independent on temperature and $\mathrm{Yb}$ concentration. More generally, a correlation between the valence of the filler atom in the $A_{y} \mathrm{Co}_{4} \mathrm{Sb}_{12}(A=$ electropositive element $)$ skutterudites on the one side and the electronic mobility and power factor on the other side could be established $\left(P F\left(A^{3+}\right)\right.$ or $\mu\left(A^{3+}\right)<$ $P F\left(A^{2+}\right)$ or $\mu\left(A^{2+}\right)<P F\left(A^{1+}\right)$ or $\left.\mu\left(A^{1+}\right)\right)$. The trivalent contribution found in the XANES spectra could be ascribed to $\mathrm{Yb}_{2} \mathrm{O}_{3}$ as an impurity phase formed when grinding the sample 
in air into a fine powder. This spurious reaction leads to the decrease of the actual ytterbium concentration in the skutterudite and to the occurrence of an insulating secondary phase, which most likely impedes the thermoelectric properties of $\mathrm{Yb}_{y} \mathrm{Co}_{4} \mathrm{Sb}_{12}$. To avoid this effect, all the subsequent samples were ground in a glove box under $\mathrm{Ar}$ atmosphere. This led to a very good control of the effective ytterbium concentration in the skutterudite, equal to the nominal one when smaller than the solubility limit. This last parameter, determined by XRD, EPMA and Hall measurements is equal to $y_{\text {lim }}=0.41 \pm 0.02$

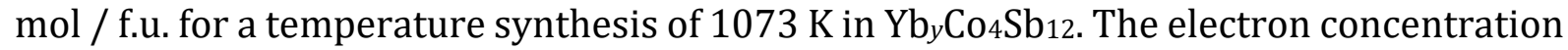
shows a complex dependence with the ytterbium (electron donor) concentration, which was discussed in terms of band(s) completion upon electron filling the CoSb3 skutterudite. For the first time, experiment and theory both agree on $n_{\text {opt }}=1.8 \pm 0.2 \times 10^{20} \mathrm{~cm}^{-3}$ being the optimum electron concentration to maximize the power factor $P F=4.2 \mathrm{~mW} \mathrm{~m}^{-1} \mathrm{~K}^{-2}$ at $300 \mathrm{~K}$ when $y=0.15$. To improve $P F$ in $\mathrm{Yb}_{y} \mathrm{Co}_{4} \mathrm{Sb}_{12}$, other research paths than playing with the $\mathrm{Yb}$ and $n$ concentrations will now be required: for instance, modification of the conduction band by resonant doping. As expected, the lattice thermal conductivity decreases with the ytterbium concentration until $y=0.35$, where it reaches $\lambda_{L}=1.3 \mathrm{~W} \mathrm{~m}^{-}$

$1 \mathrm{~K}^{-1}$. Nonetheless, the increasing electronic contribution with $y$ to the thermal conductivity balances the decrease of the lattice thermal conductivity and no decrease of the total thermal conductivity is observed beyond $y=0.15$. Finally, these electronic and thermal transport properties lead to $\mathrm{Yb}_{0.15} \mathrm{Co}_{4} \mathrm{Sb}_{12}$ being the best sample in the series with $Z T_{a v}=0.95$ over $300-800 \mathrm{~K}$ and $Z T_{\max }=1.4$ at $750 \mathrm{~K}$.

\section{Acknowledgements}

The authors acknowledge SOLEIL for supplying synchrotron radiation and more specifically thank S. Belin and. E. Fonda for their help to measure the XANES spectra in 
$\mathrm{Yb}_{y} \mathrm{Co}_{4} \mathrm{Sb}_{12}$ on the SAMBA beam line (experiment 20130264). Partial funding of this work by the "Agence Nationale de la Recherche" through the contract "Nanoskut" (ANR 12 PRGE 0008-01) is also acknowledged. 


\section{References}

1. D. T. Morelli, G. P. Meisner, B. Chen, S. Hu and C. Uher, Physical Review B, 1997, 56, 7376.

2. G. S. Nolas, M. Kaeser, R. T. Littleton and T. M. Tritt, Applied Physics Letters, 2000, 77, 1855.

3. S. Wang, J. Yang, L. Wu, P. Wei, W. Zhang and J. Yang, Advanced Functional Materials, 2015, 25, 6660.

4. Y. Tang, R. Hanus, G. J. Snyder and S.-W. Chen, Nature communications, 2015, 6, 7584.

5. J. S. Dyck, W. Chen, C. Uher, L. Chen, X. Tiang and T. Hirai, Journal of Applied Physics, 2002, 91, 3698.

6. T. He, J. Chen, H. D. Rosenfeld and M. A. Subramanian, Chemistry of Materials, 2006, 18, 759 .

7. J. Leszczynski, V. D. Ros, B. Lenoir, A. Dauscher, C. Candolfi, P. Masschelein, J. Hejtmanek, K. Kutorasinski, J. Tobola, R. I. Smith, C. Stiewe and E. Muller, Journal of Physics D: Applied Physics, 2013, 46, 495106 (495113pp).

8. Y. Tang, Y. Qiu, L. Xi, X. Shi, W. Zhang, L. Chen, S.-M. Tseng, S.-w. Chen and G. J. Snyder, Energy \& Environmental Science, 2014, 7, 812-819.

9. E. Visnow, C. P. Heinrich, P. Leidich, W. Tremel, C. P. Heinrich, A. Schmitz, B. J. de, W. E. Muller, B. Klobes, R. P. Hermann, R. P. Hermann and W. E. Muller, Inorganic chemistry, 2015, 54, 7818-7827.

10. M. Benyahia, V. Ohorodniichuk, E. Leroy, A. Dauscher, B. Lenoir and E. Alleno, Journal of Alloys and Compounds, 2018, 735, 1096-1104.

11. M. M. Koza, M. R. Johnson, R. Viennois, H. Mutka, L. Girard and D. Ravot, Nature Materials, 2008, 7, 805-810. 
12. X. Shi, J. Yang, J. R. Salvador, M. Chi, J. Y. Cho, H. Wang, S. Bai, J. Yang, W. Zhang and L. Chen, Journal of the American Chemical Society, 2011, 133, 7837-7846.

13. P.-a. Zong, X. Chen, Y. Zhu, Z. Liu, Y. Zeng and L. Chen, Journal of Materials Chemistry A, 2015, 3, 8643-8649.

14. V. V. Khovaylo, T. A. Korolkov, A. I. Voronin, M. V. Gorshenkov and A. T. Burkov, Journal of Materials Chemistry A, 2017, 5, 3541-3546.

15. X. Meng, Z. Liu, B. Cui, D. Qin, H. Geng, W. Cai, L. Fu, J. He, Z. Ren and J. Sui, Adv. Energy Mater., 2017, 7, 1602582.

16. S. Lee, K. H. Lee, Y.-M. Kim, H. S. Kim, G. J. Snyder, S. Baik and S. W. Kim, Acta Mater., 2018, 142, 8-17.

17. Z. Zhou, M. T. Agne, Q. Zhang, S. Wan, Q. Song, Q. Xu, X. Lu, S. Gu, Y. Fan, W. Jiang, G. J. Snyder and L. Wang, Journal of Materiomics, 2019, DOI: https://doi.org/10.1016/j.jmat.2019.04.008.

18. D. Qin, H. Wu, S. Cai, J. Zhu, B. Cui, L. Yin, H. Qin, W. Shi, Y. Zhang, Q. Zhang, W. Liu, J. Cao, S. J. Pennycook, W. Cai and J. Sui, Advanced Energy Materials, 2019, 9, 1902435.

19. Z. Liu, X. Meng, D. Qin, B. Cui, H. Wu, Y. Zhang, S. J. Pennycook, W. Cai and J. Sui, Journal of Materials Chemistry C, 2019, 7, 13622-13631.

20. H. Li, X. Tang, Q. Zhang and C. Uher, Applied Physics Letters, 2009, 94, 102114102113.

21. K. Biswas, M. S. Good, K. C. Roberts, M. A. Subramanian and T. J. Hendricks, Journal of Materials Research, 2011, 26, 1827-1835.

22. G. Rogl, A. Grytsiv, P. Rogl, N. Peranio, E. Bauer, M. Zehetbauer and O. Eibl, Acta Materialia, 2014, 63, 30-43. 
23. G. Rogl, A. Grytsiv, K. Yubuta, S. Puchegger, E. Bauer, C. Raju, R. C. Mallik and P. Rogl, Acta Materialia, 2015, 95, 201-211.

24. Z. Xiong, X. Chen, X. Huang, S. Bai and L. Chen, Acta Materialia, 2010, 58, 39954002.

25. Y. Tang, S.-W. Chen and G. J. Snyder, Journal of Materiomics, 2015, 1, 75-84.

26. S. Wang, J. R. Salvador, J. Yang, P. Wei, B. Duan and J. Yang, NPG Asia Mater, 2016, 8, e285.

27. J. Yang, Q. Hao, H. Wang, Y. C. Lan, Q. Y. He, A. Minnich, D. Z. Wang, J. A. Harriman, V. M. Varki, M. S. Dresselhaus, G. Chen and Z. F. Ren, Physical Review $B, 2009, \mathbf{8 0}, 115329$.

28. L. D. Chen, T. Kawahara, X. F. Tang, T. Goto, T. Hirai, J. S. Dyck, W. Chen and C. Uher, Journal of Applied Physics, 2001, 90, 1864.

29. Z. G. Mei, W. Zhang, L. D. Chen and J. Yang, Physical Review B, 2006, 74, 153202.

30. X. Shi, W. Zhang, L. D. Chen, J. Yang and C. Uher, Acta Materialia, 2008, 56, 17331740.

31. B. Ryll, A. Schmitz, J. de Boor, A. Franz, P. S. Whitfield, M. Reehuis, A. Hoser, E. Muller, K. Habicht and K. Fritsch, ACS Appl. Energy Mater., 2017, 1, 113.

32. Y. Z. Pei, J. Yang, L. D. Chen, W. Zhang, J. R. Salvador and J. Yang, Applied Physics Letters, 2009, 95, 042101-042103.

33. Y. Kajikawa, Journal of Alloys and Compounds, 2016, 664, 338-350.

34. Y. Tang, Z. M. Gibbs, L. A. Agapito, G. Li, H.-S. Kim, M. B. Nardelli, S. Curtarolo and G. J. Snyder, Nature Materials, 2015, 14, 1923.

35. E. Alleno, E. Zehani and O. Rouleau, Journal of Alloys and Compounds, 2013, 572, 43. 
36. R. Hanus, X. Guo, Y. Tang, G. Li, G. J. Snyder and W. G. Zeier, Chem. Mater., 2017, 29, 1156.

37. E. Bauer, Le Tuan, R. Hauser, E. Gratz, T. Holubar, G. Hilscher, H. Michor, W. Perthold, C. Godart, E. Alleno and K. Hiebl, Physical Review B, 1995, 52, 4327.

38. F. Grandjean, G. J. Long, B. Mahieu, J. Yang, G. P. Meisner and D. T. Morelli, Journal of Applied Physics, 2003, 94, 6683.

39. X. Y. Zhao, X. Shi, L. D. Chen, W. Q. Zhang, W. B. Zhang and Y. Z. Pei, Journal of Applied Physics, 2006, 99, 053711.

40. S. Q. Bai, X. Y. Huang, L. D. Chen, W. Zhang, X. Y. Zhao and Y. F. Zhou, applied physics A: Materials Science \& processing, 2010, 100, 1109 - 1114.

41. Y. Hu, N. Chen, J. P. Clancy, J. R. Salvador, C.-Y. Kim, X. Shi, Q. Li and Y.-J. Kim, Physical Review B, 2017, 96, 224107.

42. J. Rodriguez-Carvajal, Physica B, 1993, 192, 55-69.

43. S. Belin, V. Briois, A. Traverse, M. Idir, T. Moreno and M. Ribbens, Physica Scripta, 2005, DOI: 10.1238/physica.topical.115a00980, 980.

44. A. Michalowicz, J. Moscovici, D. Muller-Bouvet and K. Provost, Journal of Physics: Conference Series, 2009, 190, 012034.

45. O. Rouleau and E. Alleno, Review of Scientific Instruments, 2013, 84, 105103.

46. E. Alleno, D. Bérardan, C. Byl, C. Candolfi, R. Daou, R. Decourt, E. Guilmeau, S. Hébert, J. Hejtmanek, B. Lenoir, P. Masschelein, V. Ohorodnichuk, M. Pollet, S. Populoh, D. Ravot, O. Rouleau and M. Soulier, Review of Scientific Instruments, $2015,86,011301$.

47. C. Godart, L. C. Gupta and M. F. Ravet-Krill, Journal of the Less-Common Metals, 1983, 94, 187. 
48. J. Eilertsen, S. Rouvimov and M. A. Subramanian, Acta Materialia, 2012, 60, $2178-$ 2185.

49. E. B. Isaacs and C. Wolverton, Chemistry of Materials, 2019, 31, 6154-6162.

50. T. Caillat, Journal of Physics and Chemistry of Solids, 1996, 57, 1351-1358.

51. R. E. Bodnar, H. Steinfink and K. S. V. L. Narasimhan, Journal of Applied Physics, 1968, 39, 1485-1489.

52. X. Y. Zhao, X. Shi, L. D. Chen, W. Q. Zhang, S. Q. Bai, Y. Z. Pei and X. Y. Li, Applied Physics Letters, 2006, 89, 092121.

53. A. Grytsiv, P. Rogl, H. Michor, E. Bauer and G. Giester, Journal of Electronic Materials, 2013, 42, 2940-2952.

54. H. Anno, K. Matsubara, Y. Notohara, T. Sakakibara and H. Tashiro, Journal of Applied Physics, 1999, 86, 3780.

55. G. S. Nolas, J. Sharp and H. J. Goldsmid, Thermoelectrics: Basic principles and new materials developments, Springer, Berlin, Heidelberg, New-York, 2001.

56. V. Da Ros, Thèse, Institut National Polytechnique de Lorraine, 2008.

57. T. Caillat, A. Borshchevsky and J. P. Fleurial, Journal of Applied Physics, 1996, 80, 4442.

58. R. B. Dingle, The London, Edinburgh, and Dublin Philosophical Magazine and Journal of Science, 1955, 46, 831-840.

59. K. Ellmer, Journal of Physics D: Applied Physics, 2001, 34, 3097-3108.

60. S. Q. Bai, X. Shi and L. D. Chen, Applied Physics Letters, 2010, 96, 202102-202103. 


\begin{tabular}{lccc}
\hline Nominal $y$ & $\begin{array}{c}a \text { before milling } \\
(\AA)\end{array}$ & $\begin{array}{c}a \text { after milling } \\
(\AA)\end{array}$ & $\begin{array}{c}\text { Effective } y \text { after } \\
\text { milling }\end{array}$ \\
\hline 0.10 & 9.044 & 9.039 & 0.03 \\
0.15 & 9.049 & 9.042 & 0.07 \\
0.20 & 9.052 & 9.045 & 0.10 \\
\hline
\end{tabular}

Table I: Nominal ytterbium concentration, lattice parameter $(a)$ before and after milling and effective ytterbium concentration in $\mathrm{Yb}_{y} \mathrm{Co}_{4} \mathrm{Sb}_{12}(y=0.10,0.15,0.20$; set1) 


\begin{tabular}{|c|c|c|c|c|c|}
\hline $\begin{array}{c}\text { Nominal } \\
\text { composition }\end{array}$ & EPMA composition & $n\left(10^{20} \mathrm{~cm}^{-3}\right)$ & $\rho(\mu \Omega \mathrm{m})$ & $\alpha\left(\mu \mathrm{VK}^{-1}\right)$ & $\mu\left(\mathrm{cm}^{2} \mathrm{~V}^{-1} \mathrm{~s}^{-1}\right)$ \\
\hline $\mathrm{Yb}_{0.05} \mathrm{Co}_{4} \mathrm{Sb}_{12}$ & $\mathrm{Yb}_{0.04(2)} \mathrm{Co}_{4} \mathrm{Sb}_{11.73(2)}$ & 0.46 & 17 & -223 & 81.8 \\
\hline $\mathrm{Yb}_{0.10} \mathrm{Co}_{4} \mathrm{Sb}_{12}$ & - & 1.3 & 7.1 & -169 & 70.2 \\
\hline $\mathrm{Yb}_{0.11} \mathrm{Co}_{4} \mathrm{Sb}_{12}$ & $\mathrm{Yb}_{0.10(1)} \mathrm{Co}_{4} \mathrm{Sb}_{11.84(2)}$ & 1.4 & 6.7 & -161 & 66.0 \\
\hline $\mathrm{Yb}_{0.15} \mathrm{Co}_{4} \mathrm{Sb}_{12}$ & $\mathrm{Yb}_{0.13(2)} \mathrm{Co}_{4} \mathrm{Sb}_{11.78(2)}$ & 2.3 & 4.7 & -142 & 57.4 \\
\hline $\mathrm{Yb}_{0.20} \mathrm{Co}_{4} \mathrm{Sb}_{12}$ & $\mathrm{Yb}_{0.20(2)} \mathrm{Co}_{4} \mathrm{Sb}_{11.80(2)}$ & 3.9 & 3.6 & -111 & 45.5 \\
\hline $\mathrm{Yb}_{0.25} \mathrm{Co}_{4} \mathrm{Sb}_{12}$ & $\mathrm{Yb}_{0.24(2)} \mathrm{Co}_{4} \mathrm{Sb}_{11.79(2)}$ & 5.2 & 3.3 & -101 & 36.9 \\
\hline $\mathrm{Yb}_{0.30} \mathrm{Co}_{4} \mathrm{Sb}_{12}$ & $\mathrm{Yb}_{0.29(2)} \mathrm{Co}_{4} \mathrm{Sb}_{11.78(2)}$ & 6.9 & 2.9 & -90 & 30.9 \\
\hline $\mathrm{Yb}_{0.35} \mathrm{Co}_{4} \mathrm{Sb}_{12}$ & $\mathrm{Yb}_{0.33(2)} \mathrm{Co}_{4} \mathrm{Sb}_{11.77(2)}$ & 9.8 & 2.7 & -85 & 23.4 \\
\hline $\mathrm{Yb}_{0.40} \mathrm{Co}_{4} \mathrm{Sb}_{12}$ & $\mathrm{Yb}_{0.40(2)} \mathrm{Co}_{4} \mathrm{Sb}_{11.83(2)}$ & 15 & 2.6 & -69 & 16.4 \\
\hline $\mathrm{Yb}_{0.50} \mathrm{Co}_{4} \mathrm{Sb}_{12}$ & $\mathrm{Yb}_{0.41(2)} \mathrm{Co}_{4} \mathrm{Sb}_{11.75(2)}$ & 15 & 2.7 & -66 & 15.3 \\
\hline $\mathrm{Yb}_{0.60} \mathrm{Co}_{4} \mathrm{Sb}_{12}$ & $\mathrm{Yb}_{0.42(2)} \mathrm{Co}_{4} \mathrm{Sb}_{11.86(2)}$ & 14 & 2.8 & -71 & 16.1 \\
\hline
\end{tabular}

Table II. Nominal composition, composition measured by EPMA, electron concentration $(n)$, electrical resistivity $(\rho)$, Seebeck coefficient $(\alpha)$ in $\mathrm{Yb}_{\mathrm{y}} \mathrm{Co}_{4} \mathrm{Sb}_{12}$ (set2) at $300 \mathrm{~K}$. 

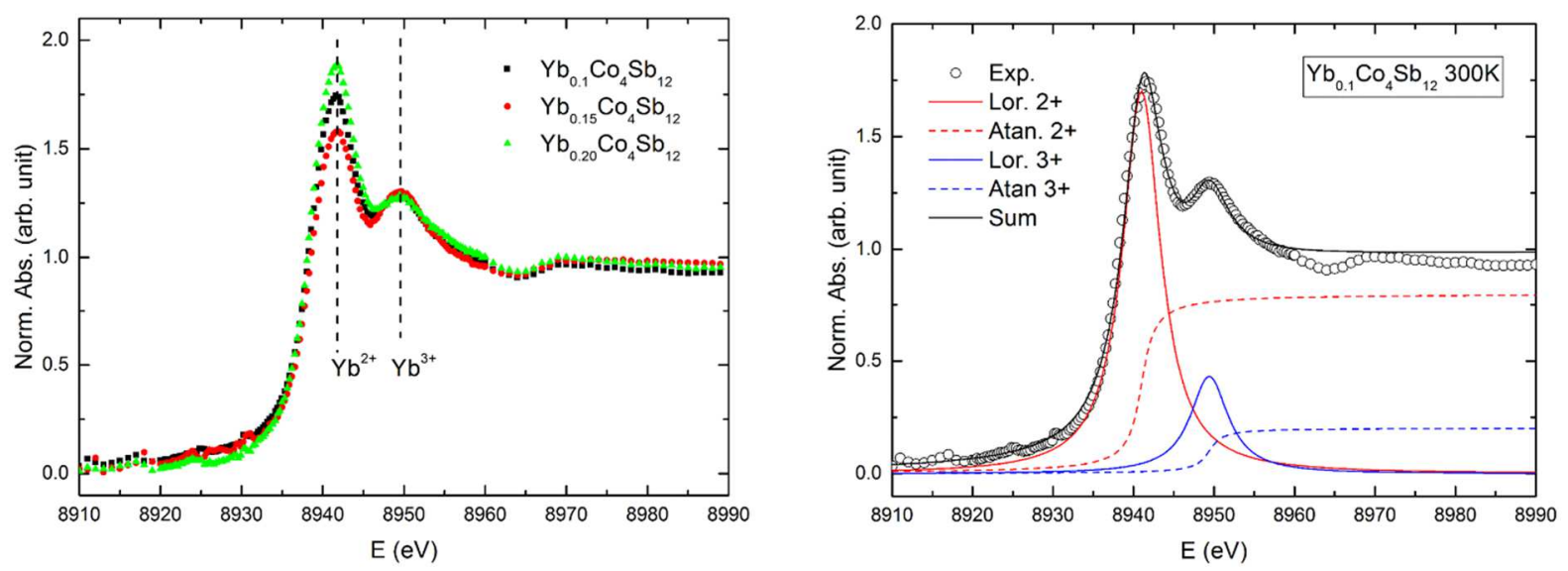

Fig. 1. a. Experimental $\mathrm{Yb}$ LIII $\mathrm{X}$-ray absorption edge versus energy throughout the $\mathrm{Yb}_{\mathrm{y}} \mathrm{Co}_{4} \mathrm{Sb}_{12}$ series $(300 \mathrm{~K})$. The dotted vertical lines indicate the position of the peaks for $\mathrm{Yb}^{2+}$ and $\mathrm{Yb}^{3+}$ valence respectively. b. $\mathrm{Yb}_{0.1} \mathrm{Co}_{4} \mathrm{Sb}_{12}$ experimental spectrum and its deconvolution in two (arctangent and Lorentzian) components corresponding to each valence state. 

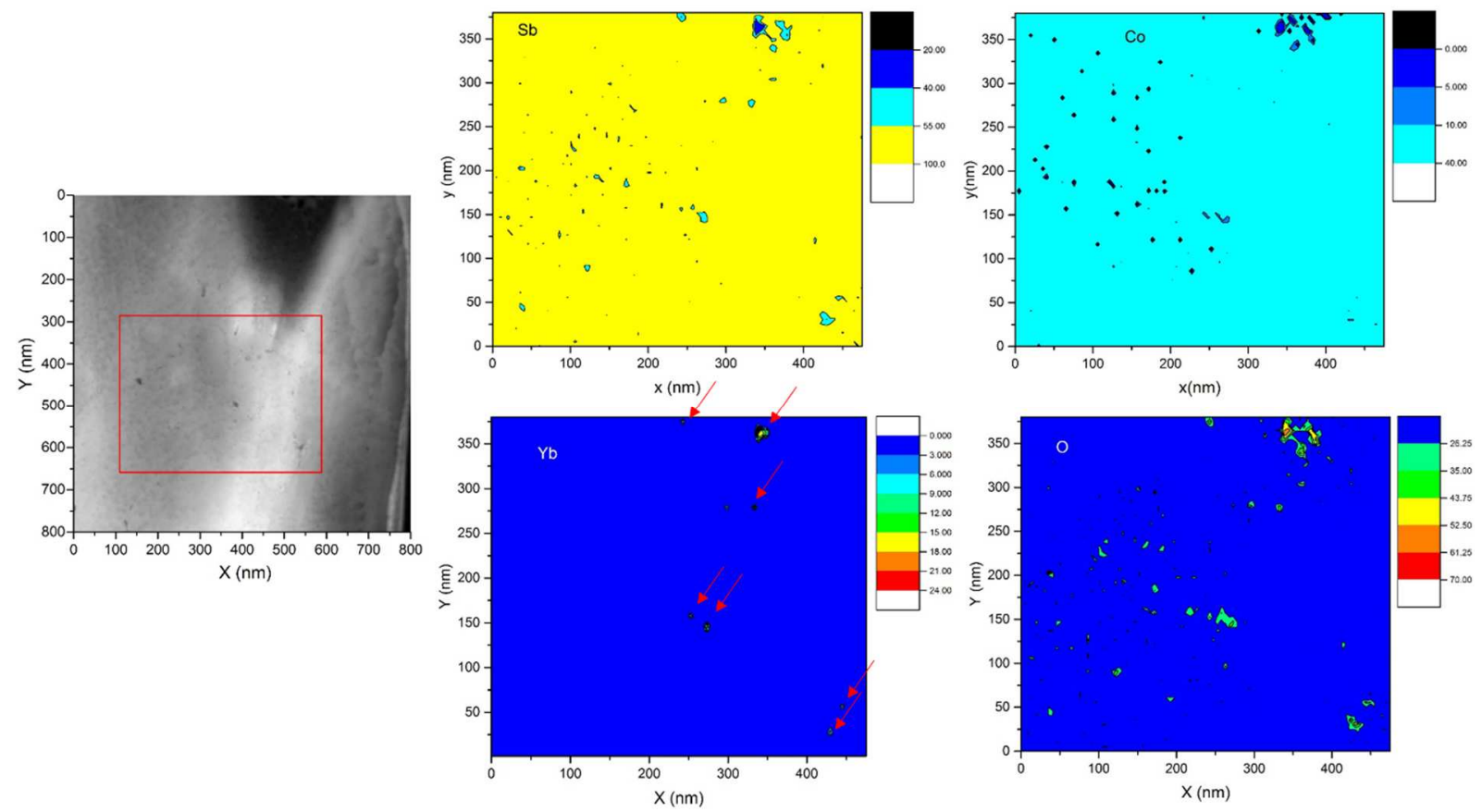

Fig. 2. Scanning transmission electron microscope images in $\mathrm{Yb}_{0.2} \mathrm{Co}_{4} \mathrm{Sb}_{12}$ (set1). STEM image (left side) and elemental EDX images ( $\mathrm{Sb}, \mathrm{Co}, \mathrm{Yb}, \mathrm{O}$ ). The $\mathrm{YbO}_{\mathrm{x}}$ nanoprecipitates are indicated by red arrows in the $\mathrm{Yb}$ elemental image. 


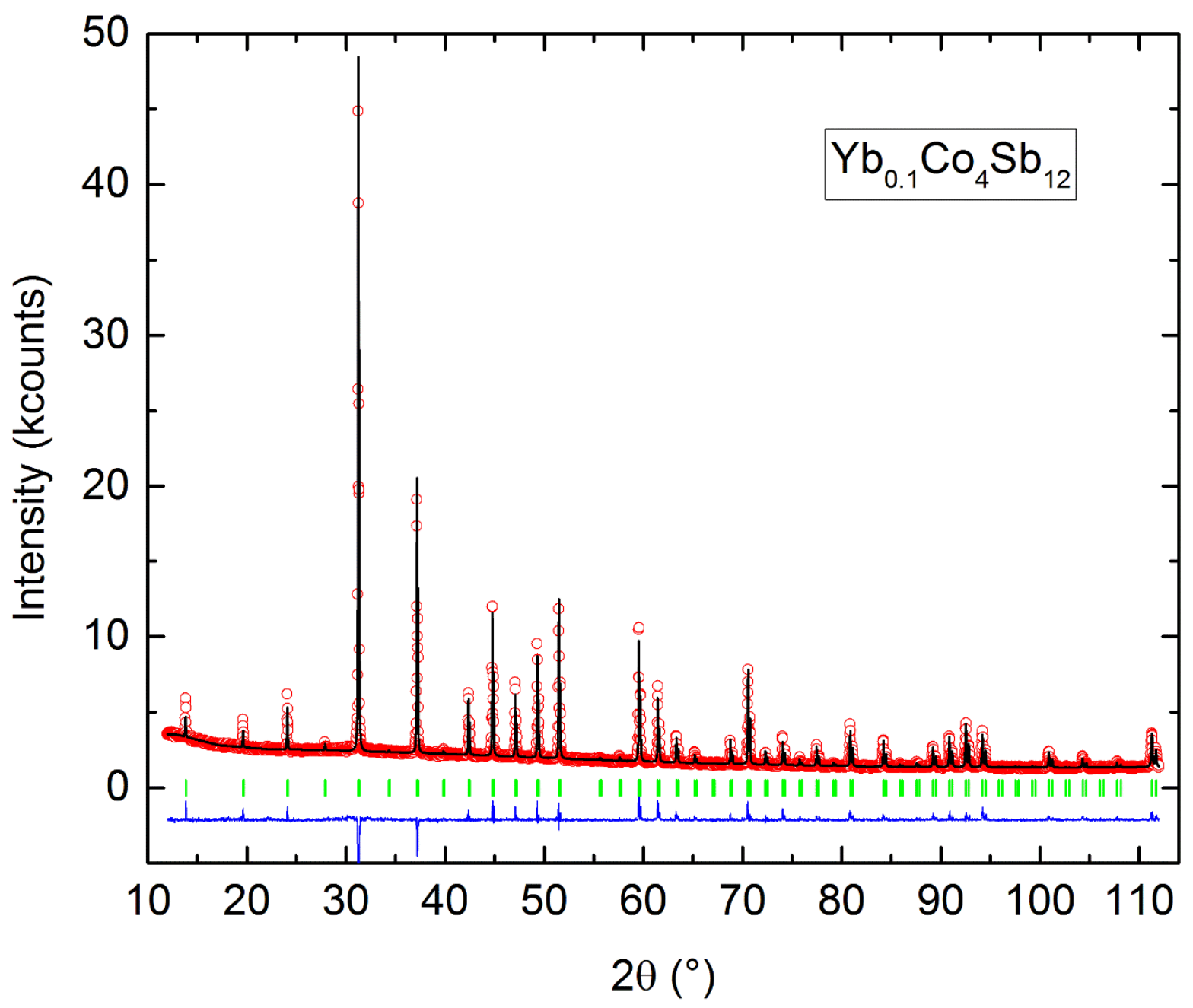

Fig. 3. Rietveld refinement of the X-ray diffraction pattern of $\mathrm{Yb}_{0.10} \mathrm{Co}_{4} \mathrm{Sb}_{12}$ (set2). Open circles are the experimental data, the line through the data is the calculated pattern, the bottom ticks are the Bragg position and the bottom line is the difference between experiment and calculation. 


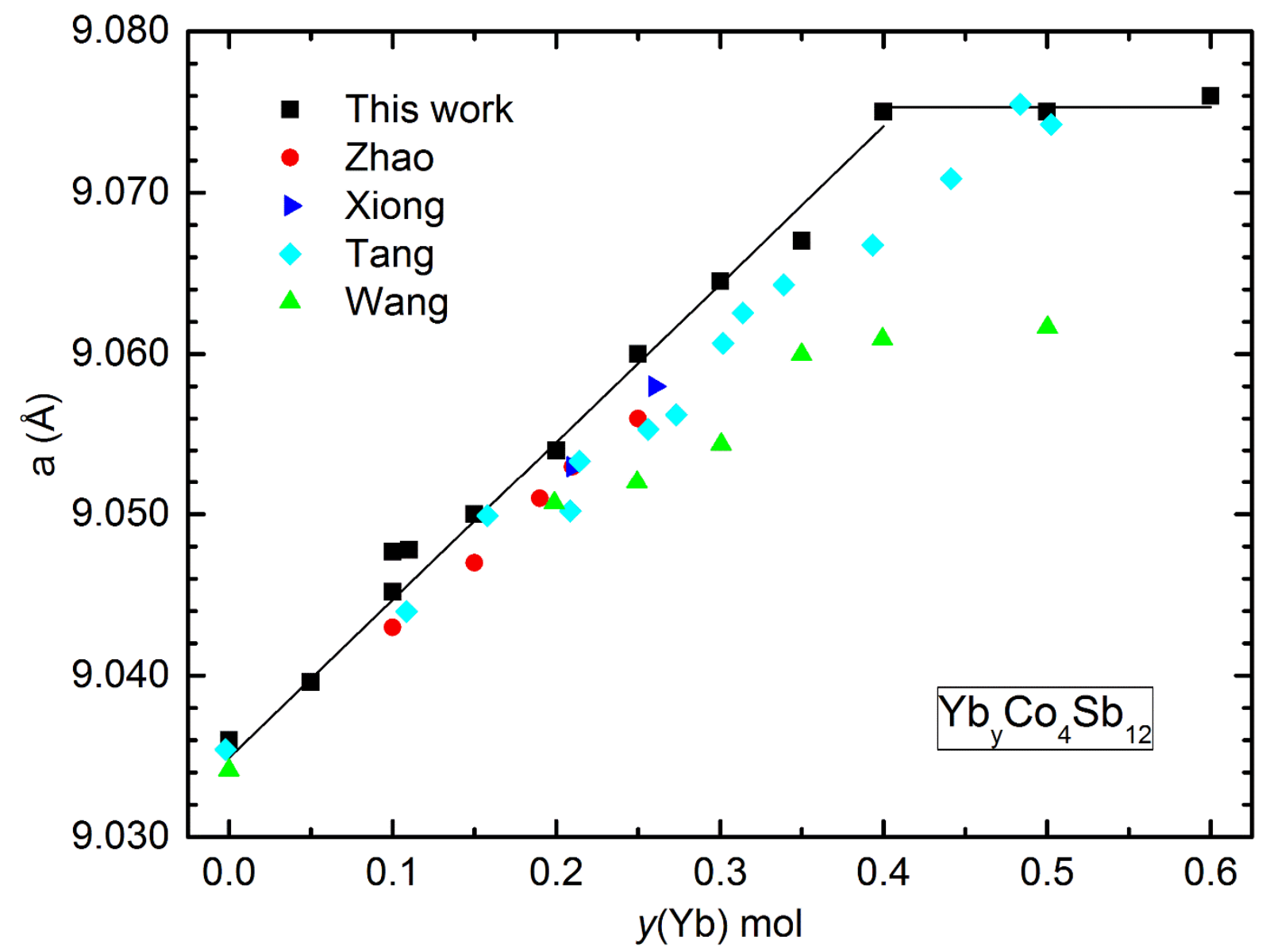

Fig. 4. Lattice parameter $(a)$ as a function of ytterbium nominal concentration $(y)$ in the $\mathrm{Yb}_{y} \mathrm{Co}_{4} \mathrm{Sb}_{12}$ samples (set2) compared to the values of Zhao et al. ${ }^{52}$, Xiong et al. ${ }^{24}$, Tang et al. ${ }^{25}$ and Wang et al. ${ }^{26}$. (the values of Tang et al. are presented as a function of $y$ measured by EPMA). The symbols are the experimental data whereas the solid lines are linear fits. 


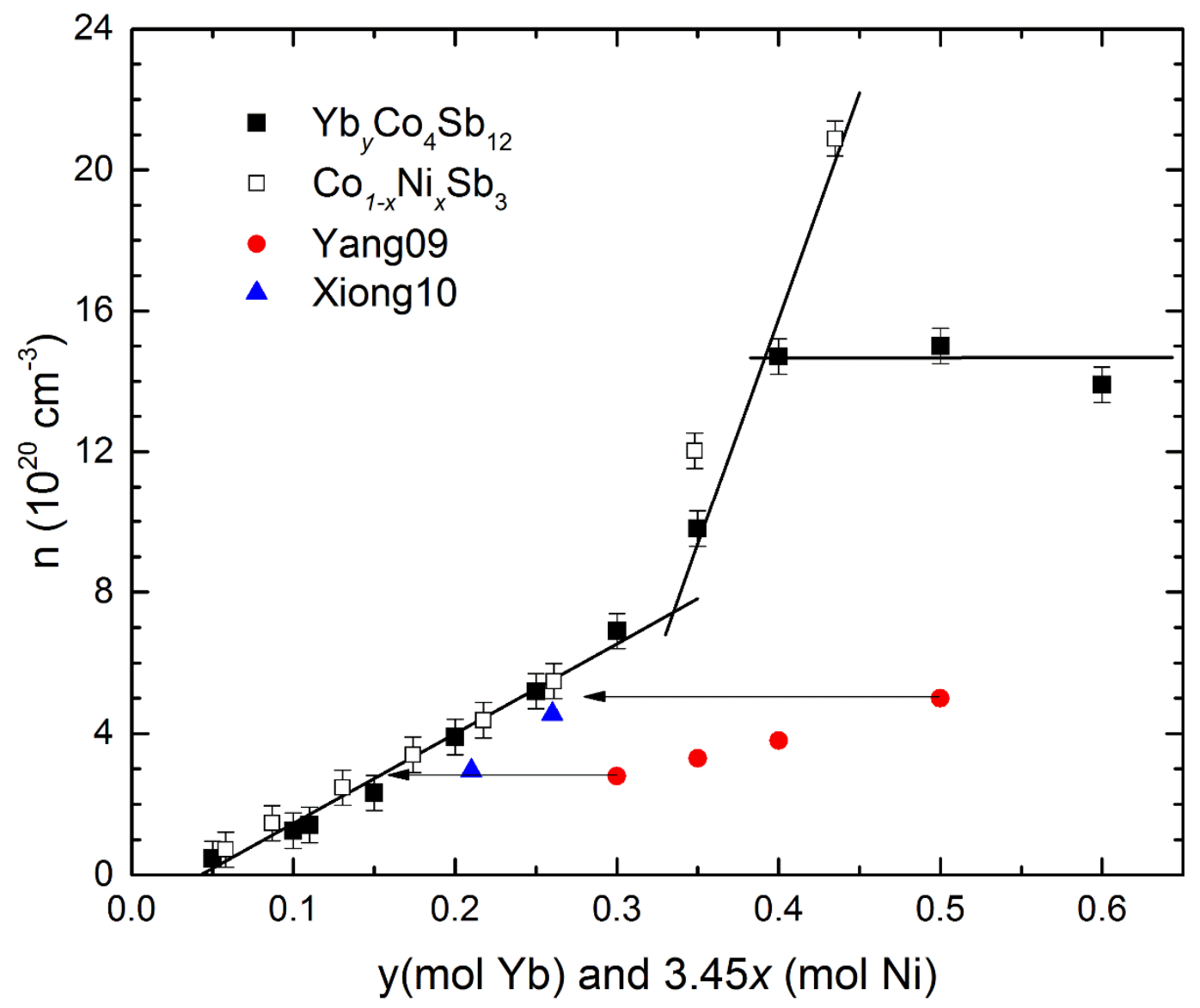

Fig. 5. Variations of the measured electron concentration with the ytterbium concentration in $\mathrm{Yb}_{y} \mathrm{Co}_{4} \mathrm{Sb}_{12}$ at $300 \mathrm{~K}$. The present data (black squares) are compared to $\mathrm{Co}_{1-\mathrm{x}} \mathrm{Ni}_{\mathrm{x}} \mathrm{Sb}_{3}$ data by Alleno et al. ${ }^{35}$ (open squares) and to other $\mathrm{Yb}_{y} \mathrm{Co}_{4} \mathrm{Sb}_{12}$ data by Yang et al. ${ }^{27}$ (red circles) and by Xiong et al. ${ }^{24}$ (blue triangles). The solid lines are linear fit to the present experimental data. 


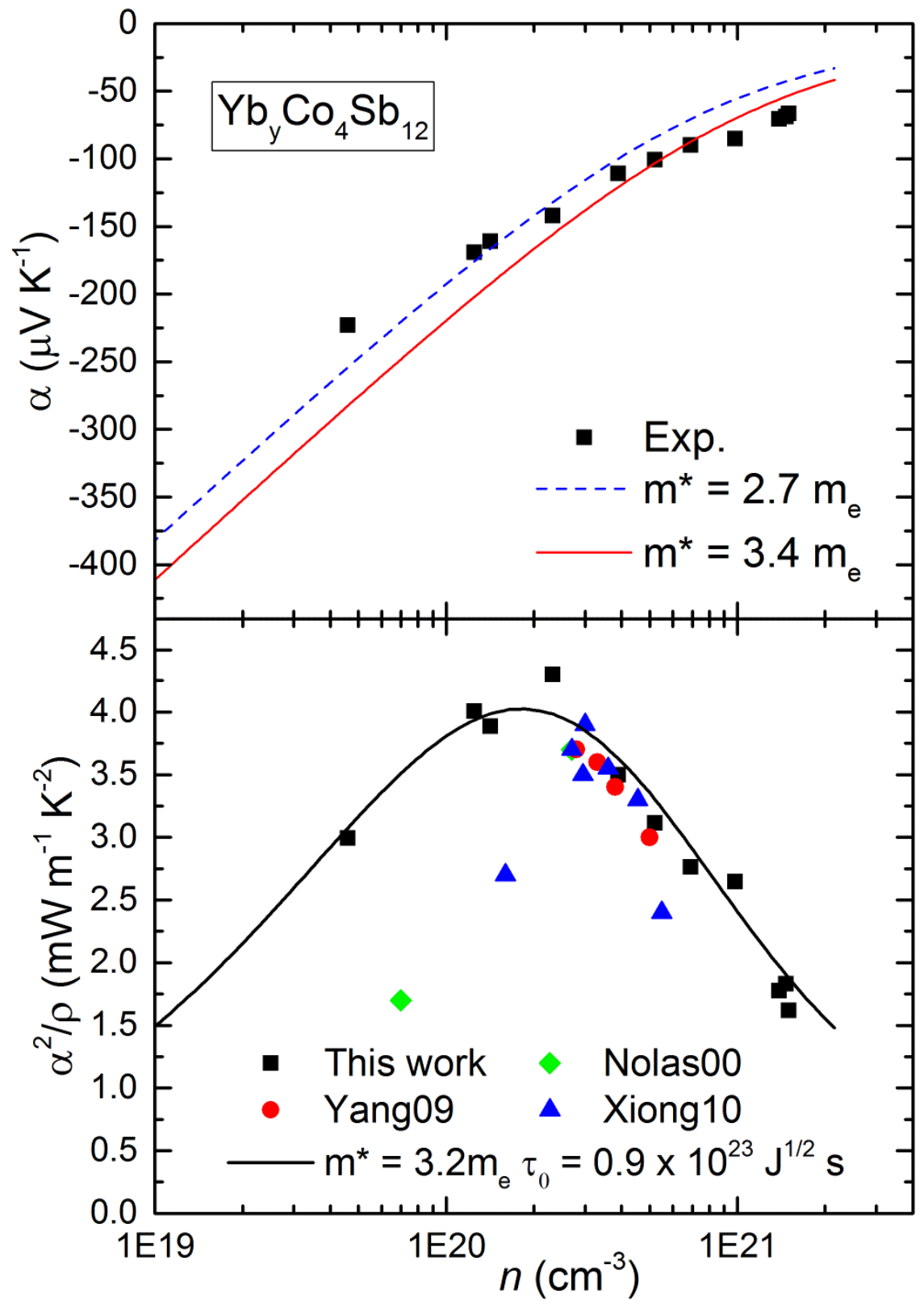

Fig. 6. a. Seebeck coefficient as a function of the Hall electron concentration in $\mathrm{Yb}_{y} \mathrm{Co}_{4} \mathrm{Sb}_{12}$. Black squares: experimental data; dashed blue and continuous red lines: fits of a single parabolic band model with an effective mass $m^{*}=2.7 \mathrm{~m}_{\mathrm{e}}$ and $m^{*}=3.4 \mathrm{~m}_{\mathrm{e}}$ respectively. $\mathrm{b}$. Power factor $P F=\alpha^{2} / \rho$ at $300 \mathrm{~K}$ as a function of the electron concentration. Solid symbols: experimental data from this work and from Nolas et al. ${ }^{2}$, Yang et al. ${ }^{27}$ and Xiong et al. ${ }^{24}$; solid line: fit of a single parabolic band model with an effective mass $m^{*}=3.2 m_{e}$ and a relaxation time parameter $\tau_{0}=0.9 \times 10^{23} \mathrm{~J}^{1 / 2} \mathrm{~s}$. 


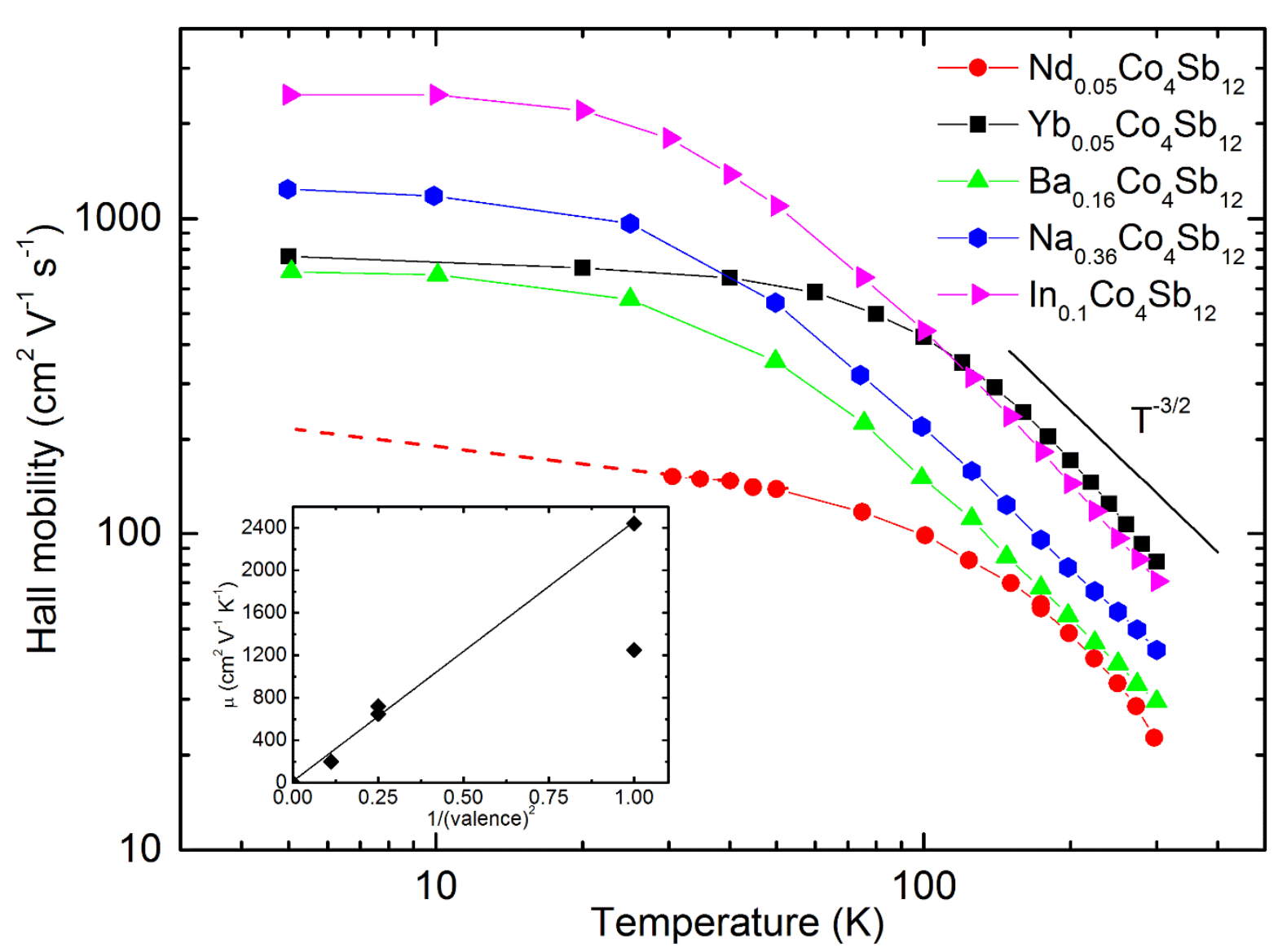

Fig. 7. Hall mobility as a function of temperature for several $A_{y} \mathrm{Co}_{4} \mathrm{Sb}_{12}$ skutterudites. Red circles: $\mathrm{Nd}^{3+}{ }_{0.05} \mathrm{Co}_{4} \mathrm{Sb}_{12}$, from ref. ${ }^{56}$. Black squares: $\mathrm{Yb}^{2+}{ }_{0.05} \mathrm{Co}_{4} \mathrm{Sb}_{12}$, present work. Green triangles: $\mathrm{Ba}^{2+}{ }_{0.16} \mathrm{Co}_{4} \mathrm{Sb}_{12}$, from ref. ${ }^{32}$. Blue hexagon: $\mathrm{Na}^{1+}{ }_{0.36} \mathrm{Co}_{4} \mathrm{Sb}_{12}$, from ref. ${ }^{32}$. $\mathrm{In}^{1+}{ }_{0.05} \mathrm{Co}_{4} \mathrm{Sb}_{12}$, from ref. ${ }^{56}$. The solid line is a $T^{-3 / 2}$ generic plot. The inset is a plot of the 10 $\mathrm{K}$ value of the Hall mobility as a function of the inverse of the square of the valence of the filler atom. 


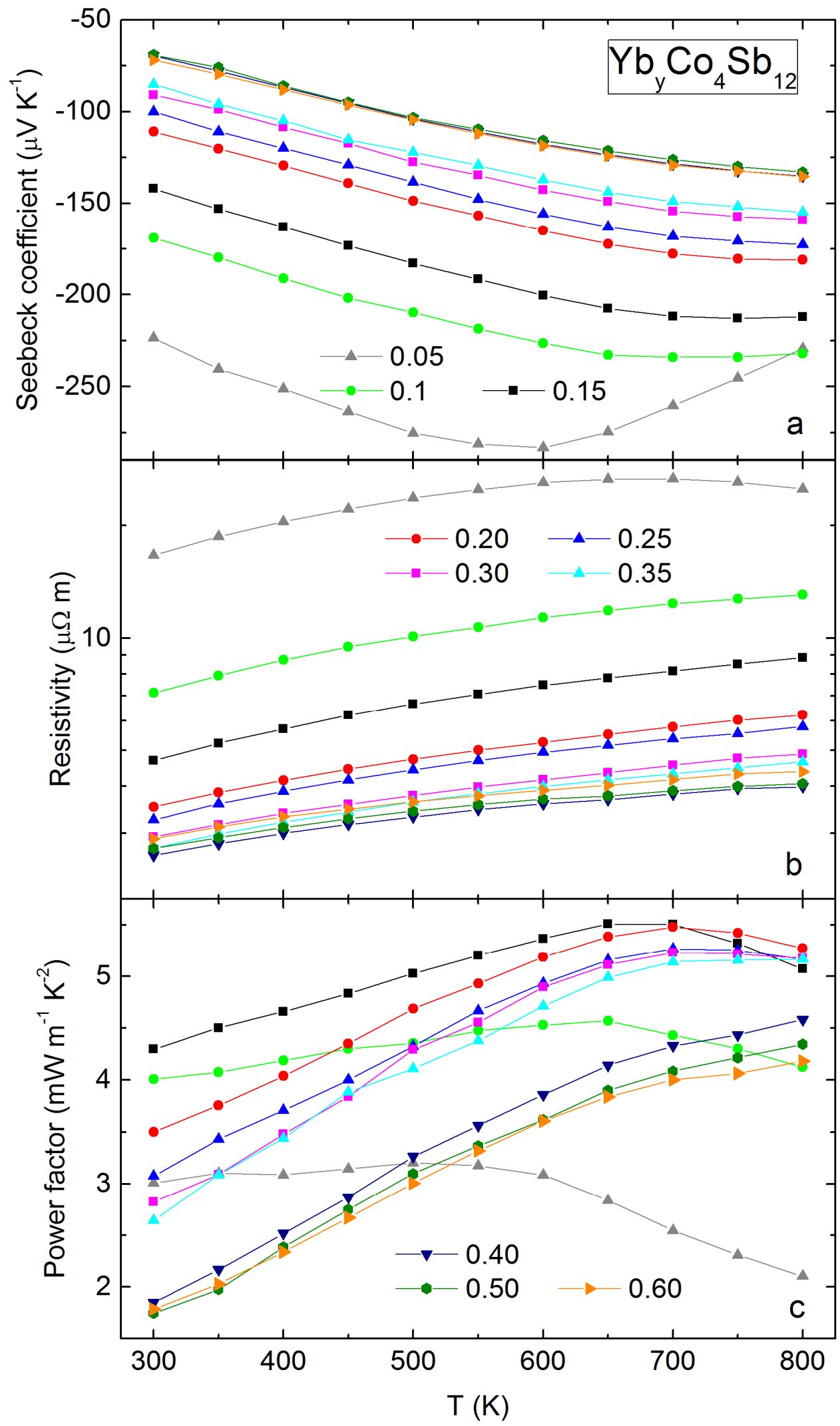

Fig. 8. Seebeck coefficient (panel a), electrical resistivity (panel b) and power factor (panel c) as a function of temperature in $\mathrm{Yb}_{y} \mathrm{Co}_{4} \mathrm{Sb}_{12}$. 


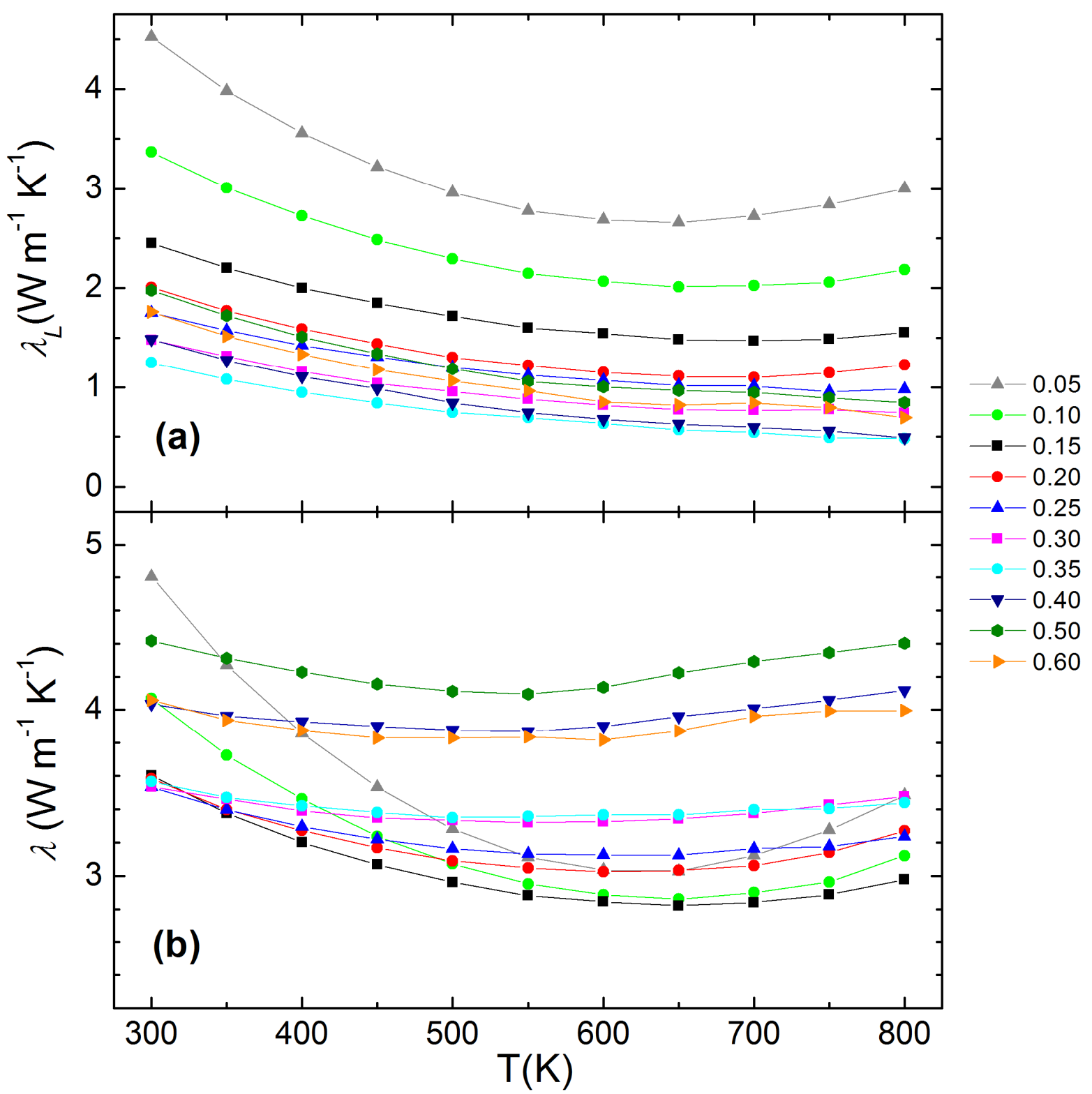

Fig. 9. a. Lattice thermal conductivity as a function of temperature in $\mathrm{Yb}_{y} \mathrm{Co}_{4} \mathrm{Sb}_{12}$. b. Total thermal conductivity as a function of temperature for the same set of samples. 


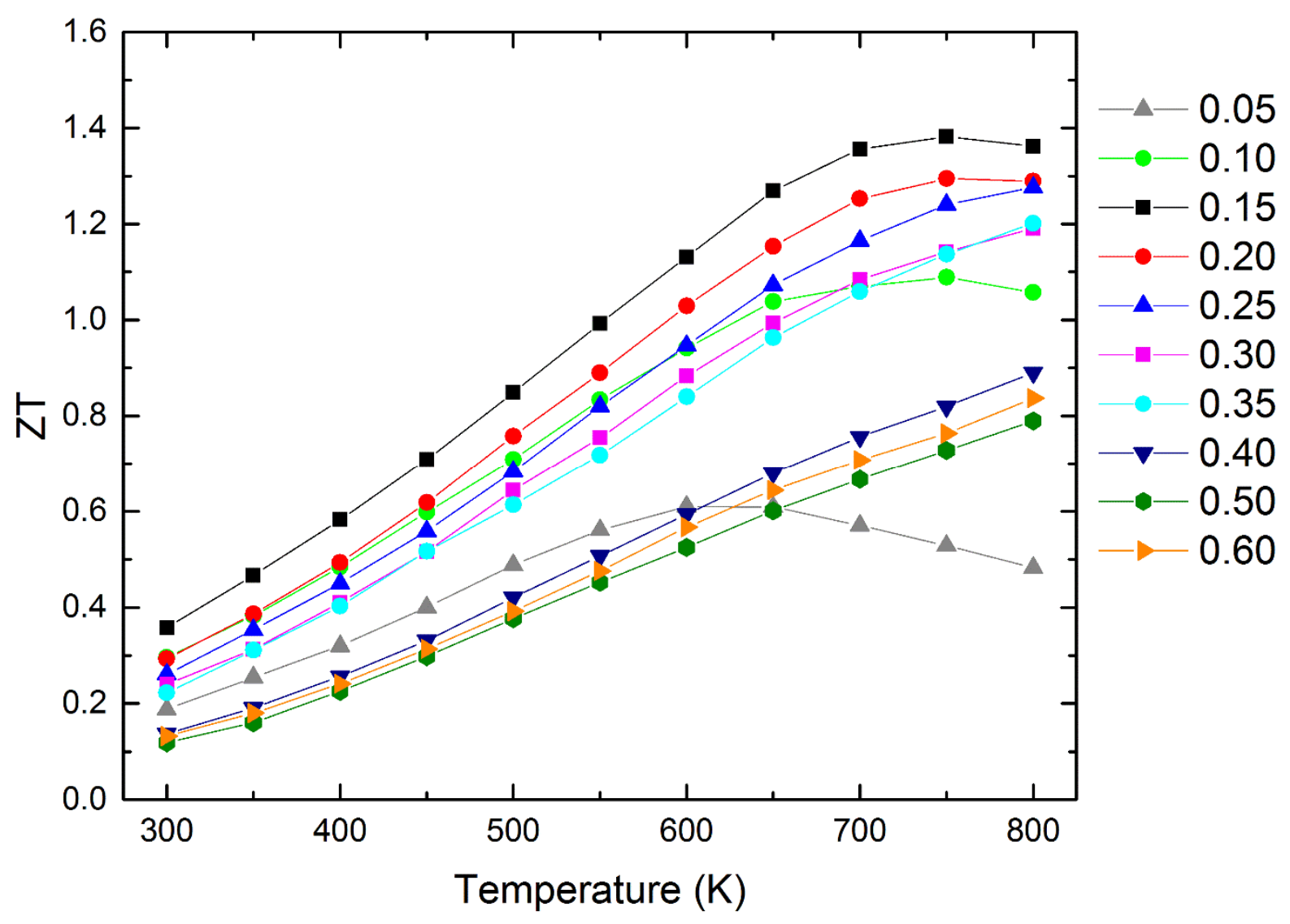

Fig. 10. Dimensionless figure of merit $\mathrm{ZT}$ as a function of temperature in $\mathrm{Yb}_{y} \mathrm{Co}_{4} \mathrm{Sb}_{12}$. 